\title{
Spatial Working Memory in Young Adolescents with Different Childhood Trajectories of Internalising, Conduct and Hyperactivity/inattention Problems
}

Ye Kuang*1, Eirini Flouri²

Department of Psychology and Human Development, UCL Institute of Education, University College London, UK

*Correspondence should be addressed to Ye Kuang, Department of Psychology and Human Development, UCL Institute of Education, University College London, 25 Woburn Square, London WC1H 0AA, UK (email: ye.kuang.17@ucl.ac.uk).

\begin{abstract}
:
Background: In children internalising and externalising problems impact on learning. However, there is limited research on the specific impact of such problems on spatial working memory (SWM), strongly related to cognitive ability and children's learning. Aims: We explored distinct trajectories of internalising problems and externalising problems (conduct problems and hyperactivity/inattention) in a large general-population sample of children followed from age 3 to age 11 years. We then assessed their role in SWM performance at age 11 years. Sample: Data were drawn from the UK's Millennium Cohort Study. Our analytic sample was children with data on SWM at age 11 years $(\mathrm{N}=12,589)$. Methods: There were two stages of data analysis. Trajectory group membership was firstly estimated by group-based trajectory modelling for internalising problems, conduct problems and hyperactivity/inattention at ages 3-11 years. Multiple regression then assessed the relationship between SWM at age 11 years and trajectory group membership after accounting for confounders. Results: Trajectories of internalising, conduct and hyperactivity/inattention symptoms across ages 3 to 11 years were related to SWM at age 11 years, even after controlling for confounding variables. For each of the three symptom domains, poor SWM was most consistently found in children with chronically high levels of symptoms. Conclusions: In general, atypical patterns of internalising problems, conduct problems and hyperactivity/inattention in childhood were related to poorer SWM in early adolescence.
\end{abstract}

Keywords: 
child psychopathology, internalising problems, conduct problems, hyperactivity/inattention, spatial working memory, group-based trajectory modelling

\section{Data availability statement:}

The MCS data that support the findings of this study are openly available in the UK Data Service

\section{Acknowledgements:}

This work was supported by the Economic and Social Research Council (ES/N007921/1). We are grateful to the Centre for Longitudinal Studies (CLS), UCL Institute of Education, for the use of these data and to the UK Data Service for making them available. However, neither CLS nor the UK Data Service bear any responsibility for the analysis or interpretation of these data. 


\section{Spatial Working Memory in Young Adolescents with Different Childhood Trajectories of Internalising, Conduct and Hyperactivity/inattention Problems}

\section{Introduction}

Spatial Working Memory (SWM) reflects the cognitive ability to manipulate spatial-visual information (Logie, 2009). SWM, also recognised as visual-spatial working memory in the model of working memory, plays an essential role in short-term memory and long-term verbal memory that uses spatial mnemonics (Baddeley \& Lieberman, 1980), and has been described as one of the two slave systems of the central executive functioning system in the model of working memory (Baddeley, 2017). Reduced SWM capacity is associated with difficulties in cognitive activities including mathematics learning (Aronen, Vuontela, Steenari, Salmi, \& Carlson, 2005; Soltanlou et al., 2019). Thus, understanding what may explain poor SWM in children in the first place is important for both prevention and intervention.

Child psychopathology, commonly categorised into internalising problems (indexing depressive and anxiety symptoms) and externalising problems (indexing hyperactivity and antisocial or 'acting-out' behaviours), has been associated with poor cognitive outcomes in general (Blanken et al., 2017; Flouri et al., 2018), but the research into its specific role in SWM is limited and showing mixed findings (Saarinen et al., 2015). For example, Blanken et al. (2017) found in their sample of 1177 children that the visuospatial processing of those with internalising and/or externalising problems appeared significantly different from that of their typically developing peers but this difference became nonsignificant when confounding was accounted for. By contrast, Martin, Davies, Cummings, and Cicchetti (2017), who followed children in 235 families from age 6 to age 14, showed that childhood emotional insecurity and attention problems predicted worse SWM in adolescence, even after adjustment. 
The evidence for a link in clinical groups or in adults is more consistent. For example, anxiety and depression seem to impact on SWM and their impact seems to vary by their severity. Christopher and MacDonald (2005), for instance, reported impairments in all components of working memory of 35 patients with clinical depression. In another study, anxiety caused by threat of shocks seemed to affect SWM in young adults, and higher levels of anxiety were related to worse SWM (Shackman et al., 2006). However, anxiety and stress did not show significant effects on SWM in Lukasik et al.'s (2019) non-clinical sample of 503 adults. Externalising disorders [Attention-Deficit/Hyperactivity Disorder (ADHD), Conduct Disorder (CD) and Oppositional Defiant Disorder (ODD) (Nivard et al., 2017)] seem to be more strongly linked to deficits in SWM, but there is significant specificity by type, with ADHD being more consistently and more strongly associated with impaired working memory in general. For example, three meta-analyses (Schoemaker, Mulder, Deković \& Matthys, 2013; Martinussen et al., 2005; Willcutt et al., 2005) reported small to large effect sizes of impaired working memory in children with ADHD, with researchers emphasising the importance of working memory deficits in the visuo-spatial domain in particular (e.g., Ferrin \& Vance, 2012; Lui \& Tannock, 2007), although null associations have also been found (Brocki, Nyberg, Thorell, \& Bohlin, 2007). Associations with ODD and CD are less consistent. Oosterlaan et al. (2005) examined performance on working memory, verbal fluency, and planning tasks in children 6 to 12 years old and reported that deficits were present in children with ADHD and those with comorbid ADHD and ODD/CD, but not in children with only ODD/CD. Likewise, Thorell and Wåhlstedt (2006) found that inhibition, working memory, and verbal fluency in preschoolers were related to ADHD, but not ODD, in both categorical and dimensional analyses. However, Saarinen et al. (2015) showed that their sample of 26 children with ODD/CD aged 7 to 12 had significantly worse SWM compared to the control group, even after controlling for ADHD 
comorbidity. More recently, Griffith et al. (2017) found that difficulties in working memory and sustained attention were related to negative affect symptoms of ODD, but not to oppositional and antagonistic behaviour.

\section{The present study}

In summary, it appears that there is an association between deficits in SWM and several domains of child psychopathology which seems to vary in strength by domain. However, most of the research to date is cross-sectional and with small, selective samples. It is therefore unclear what the association is in the general child population, especially when a longitudinal lens is applied, which is important given the temporal instability of child psychopathology symptoms in the general population. This study attempted to fill this gap using longitudinal data from the Millennium Cohort Study (MCS), a large general-population sample in the UK. In view of the increasing evidence that in the general child population the trajectories of such symptoms (broadly defined as internalising and externalising) can be divided into different types with distinct characteristics (Fanti, 2010; Flouri et al., 2018; Korhonen et al., 2018; Nivard et al., 2017), we examined in this study the role of different trajectory groups of internalising symptoms and externalising symptoms (hyperactivity/inattention and conduct problems in the present study) in later SWM performance. Given that the association between SWM and externalising symptoms differs by symptom domain, we modelled the SWM links with hyperactivity/inattention and conduct problems separately.

\section{Methodology}

\section{Participants}

Our data came from the Millennium Cohort Study (MCS), a sample of 18,818 children (in 18,552 families) who were born between 1 September 2000 and 31 August 2001 in England and Wales, and between 24 November 2000 and 11 January 2002 in Scotland and Northern 
Ireland (Connelly \& Platt, 2014). There are seven survey sweeps to date conducted when children were at an average age of 9 months, and 3, 5, 7, 11, 14, and 17 years (CLS $\mid$ Millennium Cohort Study, n.d.). The recruited sample was clustered at electoral ward level and was disproportionately stratified to overrepresent poor areas, areas with more ethnic minorities in England, and areas in Wales, Scotland and Northern Ireland (Hansen et al., 2014). Ethics approval for the MCS was obtained from NHS Multicentre Research Ethics Committees. Consent was received from parents and assent from the children themselves from age 11 years. In MCS, SWM was measured at Sweep 5, and symptoms of child psychopathology were collected via an interview with the main carer since Sweep 2. Therefore, we used data from Sweeps 2 to 5 for this study. Our analytic sample was children (singletons and first-born multiples) with data on SWM at age 11 years $(\mathrm{N}=12,589)$. For the modelling of the distinct trajectories of internalising, conduct and hyperactivity/inattention symptoms across Sweeps 25 we included all MCS children with data on symptoms on at least two sweeps. Figures 1 and 2 show the flow charts for all analyses.

[insert Figure 1 and Figure 2]

\section{Measures}

\section{Spatial working memory}

SWM was measured at age 11 with the SWM task of the Cambridge Neuropsychological Test Automated Battery (CANTAB) (Robbins et al., 1994). Participants are shown on a computer screen several coloured boxes, some of which contain blue tokens. They need to find the tokens by touching the boxes and move the tokens to a column on the screen (Figure 3 ). The difficulty level increases as the number of boxes increases from 3 to 8 . Once a token is found in a box and placed to the column, another search starts, and the token could be in any of the other boxes. A trial is completed when all the tokens from the simultaneously presented boxes are found. Responses are recorded as errors when participants touch boxes which had already been found 
empty within one search (within errors) or revisit boxes which previously contained tokens within one trial (between errors). The colour and position of the boxes changes from trial to trial to avoid the use of stereotyped search strategies. In MCS, participants had a chance to practise 3 trials with 3 boxes in each trial prior to the test. The test consisted of 3 blocks with 4 trials in each; the number of boxes increased from 4 to 6 to 8. Participants' performance was measured by total errors and strategy (Atkinson, 2015). 'Total errors' was the sum of within and between errors that participants made across trials. 'Strategy' measured participants' use of an efficient search method of returning to the same box at the beginning of each search. Strategy was recorded as the frequency of touching a box at the beginning of a search which was different from the one touched at the beginning of the previous search. Higher scores on total errors and lower scores on strategy suggested poorer SWM performance.

\section{[insert Figure 3]}

\section{Internalising, conduct and hyperactivity/inattention problems}

These were all measured using the parent-reported Strengths and Difficulties Questionnaire (SDQ) (Goodman, 1997) scores at Sweeps 2-5 (MCS 2-5). SDQ measures symptoms in four areas, namely, emotional symptoms, peer problems (both of which index internalising symptoms in the general child population, as explained), conduct problems and hyperactivity/inattention. In line with established practice (https://www.sdqinfo.org/a0.html), we considered emotional symptoms and peer problems as two types of difficulties within the one domain of internalising problems. Given that hyperactivity/inattention symptoms tend to be more consistently related to SWM than conduct problems, these two types of difficulties were analysed separately. We banded children's scores in all areas to two levels $(0=$ normal; $1=$ at risk) according to established cut-offs (Goodman, 1997) whereby children with scores below cut-off are considered 'normal' ( $80 \%$ in the general population), and those with scores above cut-off are considered 'at risk'. For internalising problems, 0 referred to scoring below 
cut-off on both emotional symptoms and peer relationships and 1 to being at risk of either emotional or peer problems.

\section{Confounding variables}

Confounding variables, that correlate with both SWM and internalising, conduct and hyperactivity/inattention problems in children, were included as covariates in the regression analyses to rule out alternative mechanisms that explain the outcome of interest (Frank, 2000). These included exact age, verbal ability, gender, maternal depression, and socio-economic status (SES) (Blasiman and Was, 2018; Voyer, Voyer, \& Saint-Aubin, 2017; Hughes et al., 2013; Dekker et al., 2007; Leve et al., 2005; Mesman et al., 2001; Cummings \& Davies, 1994). Age was children's age in months at MCS5. Verbal ability was measured at MCS5 with Verbal Similarities, a British Ability Scales (BAS) subscale for verbal knowledge and verbal reasoning ability (Elliott et al., 1996). Maternal depression was measured using the 'Kessler 6' from MCS2 to MCS5 (Kessler et al., 2003) and was given as mean number of sweeps that the mother reported as having clinically meaningful depression (above cut-off, i.e., score of 6). We approximated $\boldsymbol{S E S}$ by family poverty, maternal education and ethnicity. Family poverty was measured by the Organisation for Economic Co-operation and Development (OECD) indicator that the family was above or below the poverty line for MCS2 to MCS5. We generated a variable for the mean number of sweeps that the family was below the poverty line. Maternal education was measured by a dummy variable indicating whether the mother had a university degree or not. Ethnicity was a categorical variable of belonging to one of the 6 UK Census ethnic groups at MCS5.

\section{Analytic strategy}

Two sequential stages of data analysis were conducted in STATA. Firstly, Group-Based Trajectory Modelling (GBTM), a statistical method which allows subgroups of similar trajectories of one outcome to emerge from the data (Nagin, 2005), was used to estimate 
different trajectory groups for internalising, hyperactivity and conduct problems in childhood (ages 3-11 years). GBTM simultaneously estimates (a) the probabilities of individuals being assigned to each group by a multinomial logit model and (b) the longitudinal trajectories by polynomial functions of age (e.g., zero order as constant, first order as linear, second order as quadratic) (Hickson et al., 2020; Nagin, 2005). GBTM in our study is fitted up to a quadratic relationship because the data available were collected at 4 time-points and at least 5 are needed to fit a higher order model (King et al., 2018). For GBTM, we used Traj, a free plugin in STATA. GBTM parameters were estimated by Full Information Maximum Likelihood (Nagin, 2005). Each GBTM included age, the outcome (binary, as explained) and the sampling design weight. Several criteria were used to find the best-fitted model (Nylund-Gibson \& Choi, 2018), including the Bayesian Information Criterion (BIC), the Average Posterior Probability of Assignment (AvePP) and the Odds of Correct Classification (OCC). The second stage of data analysis explored differences in SWM by trajectory group membership, using multiple linear regression modelling. All multiple regression models, fitted using the command regress, reflected the stratification and clustering of the MCS study design by using the svy command (Ketende \& Jones, 2011). Missing data were handled with multiple imputation by chained equations (MICE) using the mi command (Jakobsen et al., 2017; Royston, 2004).

\section{Results}

\section{GBTM}

Table 1.1 presents the tetrachoric correlations and descriptive statistics for internalising, conduct and hyperactivity/inattention problems at Sweeps 2-5. Internalising, conduct and hyperactivity/inattention problems were positively correlated (all $\mathrm{p}<0.01$ ), as expected. The proportion of children at risk of internalising problems ranged from $22.79 \%$ to $29.70 \%$ across the four sweeps. In total, $51.24 \%$ children were at risk of conduct problems at MCS2, 22.57\% 
were at risk at MCS3, 20.56\% at MCS4 and 20.15\% at MCS5. For hyperactivity/inattention these proportions were, respectively, $24.79 \%, 17.95 \%, 19.76 \%$ and $17.09 \%$.

[insert table 1.1]

\section{Internalising problems}

For the GBTM of internalising problems, data on 14,226 children (total $\mathrm{N}$ of observations = $50,778)$ were used. The model fit indices of the 2 to 6 group solutions are shown in Table S1.1 of the Supplementary Material. BIC values indicated that the 4-group model was better than the other models. Children with low levels of internalising problems tended to show a stable trajectory which can be modelled as a constant polynomial function of age. Therefore, models with one group modelled as a constant function of age were tested alongside models including linear or quadratic functions of age. Table S2.1 summarizes the fit indices of these 32 4-group models. The model selected was the one with the largest BIC value and where the highestorder coefficients for each group were all significant. Figure 4 describes the four trajectory groups: 'no risk' (30.9\% of the sample), 'deteriorating' (10\%), 'low risk' (41.2\%) and 'high risk' (18\%). The 'no risk' group seemed to never show internalising symptoms across the study period. In the 'deteriorating' group, the proportion of high scorers of internalising symptoms increased sharply from age 5 (approximately 0\%) to age 7 (approximately 40\%), further increasing to $60 \%$ by age 11 . For the 'low risk' group, the proportion was approximately between $10 \%$ and $40 \%$. The 'high risk' group exhibited a relatively high proportion of high scorers (> 60\%) consistently during childhood.

[insert figure 4]

\section{Conduct problems}

For the GBTM of conduct problems, data on 14,242 children (total $\mathrm{N}$ of observations $=50,918$ ) were used. Again, the 4-group solution showed a better fit than solutions with 2, 3, 5 or 6 groups (Table S1.2). A total of 38 4-group models were subsequently assessed, including 16 
models where each group was modelled as either linear or quadratic function of age, and 22 models with up to two groups modelled as a constant function of age, as some studies (e.g., Fanti, 2010; Korhonen et al., 2018; Gutman et al., 2019) have suggested the presence of distinct groups with consistently high and consistently low symptoms. Results are shown in Table S2.2. Figure 5 depicts the four trajectories according to the best group solution. The 'deteriorating' group (5.6\%) showed an increase in proportion of high scorers from $0 \%$ at age 3 to around $30 \%$ at age 11 . For children in the 'early childhood-limited' group (51.1\%) the proportion decreased from about $30 \%$ at age 3 to about $0 \%$ at age 5 and remained low thereafter. The 'improving' group $(31.5 \%)$ reported a high proportion at age 3 (approximately $70 \%$ ) which dropped to approximately $25 \%$ at age 11 . Finally, $11.8 \%$ of the sample was assigned to the 'high risk' group. In that group, the proportion of high scorers was over $70 \%$.

\section{[insert figure 5]}

\section{Hyperactivity/inattention}

For the GBTM of hyperactivity/inattention, data on 14,249 children (total $\mathrm{N}$ of observations = 50,920) were used. Again, the 4-group model showed the largest BIC value which was higher than that of other models by at least 9 , suggesting a strong evidence for model improvement (Table S1.3). Thirty-eight 4-group models with different combinations of polynomial function

of age across 4 groups were tested, and their fit indices are presented in Table S2.3. Figure 6 describes the four trajectories according to the best group solution. The proportion of high scorers of hyperactivity/inattention problems increased from $0 \%$ at age 3 to $40 \%$ at age 11 in the 'deteriorating' group (11.8\%). The average proportion in the 'improving' group (19.4\%) dropped from approximately $60 \%$ to $30 \%$. The 'typically developing' children (62.7\%) showed a low proportion of around $10 \%$ at age 3 , which dropped to $0 \%$ at age 5 and remained stable thereafter until age 11 . Finally, the 'high risk' group (6\%) had a very high proportion which increased from about $80 \%$ at age 3 to $100 \%$ at age 11 . 
[insert figure 6]

\section{Sample characteristics (unweighted data)}

Table 1.2 indicates that the two measures for SWM were moderately correlated $(r=0.65, p$ $<.05$ ), as expected. Tables 2.1, 2.2 and 2.3 present our analytic sample's characteristics by trajectory group. As expected, the children in 'high risk' groups showed more SWM errors and less consistent strategy compared to other children. Groups with the lowest average prevalence of problem behaviours (i.e., the 'no risk' group for internalising problems, the 'early childhoodlimited' group for conduct problems and the 'typically developing' group for hyperactivity/inattention) showed the best SWM and highest verbal ability on average. The children in these groups also tended to come from more advantaged families (they were less likely to live in poverty, or with depressed or lower educated mothers). Missingness was in general low: $10 \%$ for group membership of internalising problems, $11 \%$ for that of conduct problems, and $10 \%$ for that of hyperactivity/inattention. Missingness on the covariates was less: $4 \%$ for maternal education, $0.02 \%$ for ethnicity, and $2 \%$ for maternal depression. Missing values were dealt with by MICE because missingness in the predictors of interest was, as shown, above $5 \%$ but below $40 \%$ (Jakobsen et al., 2017).

[insert tables 1.2, 2.1, 2.2, and 2.3]

\section{Multiple regression models}

For each SWM domain (errors and strategy) and for each symptom domain (internalising, conduct and hyperactivity/inattention) four models were fitted. The baseline model (Model 1) only included trajectory group membership. Model 2 added child gender and age at MCS5. Poverty, ethnicity, maternal education and maternal depression were further included in Model 3. Model 4, which added verbal ability, was the fully adjusted model. In all models, trajectory group membership, a categorical variable, was included as one of the explanatory variables; 
the group with the average lowest prevalence of problem behaviours was taken as reference, hence no coefficients are reported for that group.

\section{Internalising problems and SWM}

The results in Table 3, which show differences in SWM by internalising trajectory group, suggest that children from the 'high risk' group, the 'low risk' group and the 'deteriorating' group made significantly more search errors in the SWM task than children from the 'no risk' group $(b=3.09, \mathrm{SE}=0.60, \mathrm{p}<0.001 ; \mathrm{b}=1.33, \mathrm{SE}=0.50, \mathrm{p}<0.01$, and $\mathrm{b}=2.60, \mathrm{SE}=0.92, \mathrm{p}<$ 0.01, respectively), even after controlling for covariates. Girls, children with higher levels of verbal ability and children with university-educated mothers made fewer total errors, whereas poverty and being Black or Black British were associated with more total errors. Trajectory group membership had little impact on SWM strategy (Table 4): after full adjustment, children's SWM strategy performance no longer differed across internalising trajectory groups.

[insert tables 3 and 4]

\section{Conduct problems and SWM}

For conduct problems, results in Table 5 indicate that the 'improving' group $(b=1.38, \mathrm{SE}=$ $0.52, \mathrm{p}<0.01)$ and the 'high risk' group $(\mathrm{b}=3.25, \mathrm{SE}=0.66, \mathrm{p}<0.001)$ made more errors than the 'early childhood-limited' group. Compared to the 'early childhood-limited' group, the 'improving' group $(\mathrm{b}=0.33, \mathrm{SE}=0.16, \mathrm{p}<0.05)$ and the 'high-risk' group $(\mathrm{b}=0.70, \mathrm{SE}=$ $0.21, \mathrm{p}<0.01$ ) also showed poorer SWM strategy (Table 6).

[insert tables 5 and 6]

\section{Hyperactivity/inattention and SWM}

The impact of trajectory group membership for hyperactivity/inattention on SWM total errors and SWM strategy remained significant in the fully adjusted models. Compared to the 'typically developing' group all three other groups did worse in SWM (Tables 7-8), with the 'high risk' group performing particularly poorly. 
[insert tables 7 and 8]

\section{Discussion}

Using data from a large general-population longitudinal sample, this study delineated distinct groups of children on trajectories of internalising, conduct and hyperactivity/inattention symptoms from preschool age until the end of primary school, and investigated whether these distinct subpopulations of children differ in spatial working memory (SWM), measured at the end of the study period. We found four trajectory groups for each symptom domain, consistently with previous studies (e.g., Flouri et al, 2018; Fanti, 2010; Gutman et al., 2019).

In general, and for all three symptom domains, children with a persistently high level of symptoms across ages 3 to 11 years tended to show poorer SWM at age 11 years. Studies with animals and patient groups have suggested that abnormal dopamine-related activities in the prefrontal cortex or dramatic changes of cortisol levels could lead to subsequent poor SWM performance (e.g., Mizoguchi et al., 2000; Murphy, Arnsten, Goldman-Rakic, \& Roth, 1996; Zahrt, Taylor, Mathew, \& Arnsten, 1997; Taverniers, Ruysseveldt, Smeets, \& Grumbkow, 2010). Given that internalising and externalising problems, especially of the chronic type, are also associated with dysregulated dopamine and cortisol levels (Capaldi et al., 2012; Ruttle et al., 2011), children with atypical internalising and/or externalising symptoms may show poor SWM because prefrontal cortical dopaminergic dysfunction or HPA axis dysregulation cause both. If the relationships we identified are causal, however, then our findings suggest that poor SWM in adolescence, strongly associated with academic success, can be prevented by preventing emotional and behavioural problems in childhood and by intervening before they become chronic. 
Our study has many strengths, including that it is the first, to our knowledge, to explore differences in SWM in early adolescence by the developmental course of a broad range of emotional and behavioural symptoms across childhood. Other strengths include its large sample size, its use of two related but distinct measures of SWM, its longitudinal design, and a robust adjustment for confounders in the analysis. However, it has some important limitations as well. Firstly, model fit for the GBTM analysis, although acceptable, could be further improved by including a cubic polynomial function of age, which we could not do as we only had four sweeps of data (King et al., 2018). Secondly, there is evidence that there might be comorbidity between internalising and externalising problems (e.g., Fanti, 2010; Flouri et al., 2018). We tried to control for such comorbidity by including externalising problems as a timevarying covariate in GBTM for internalising problems and vice versa. However, the amount of variance between observed and estimated trajectory means was large and it was also difficult to obtain model estimates. As a result, we conducted GBTM for all three domains without controlling for comorbidity. Thirdly, as already discussed, we cannot determine, given the study design and the data available, if the associations we found are causal, and if so in what direction, or whether they are due to common causes. This is an important issue because establishing causality will have profound effects on planning both prevention and intervention strategies for poor SWM, in turn a strong predictor of low academic performance and educational attainment.

\section{References}

Aronen, E. T., Vuontela, V., Steenari, M.-R., Salmi, J., \& Carlson, S. (2005). Working Memory, Psychiatric Symptoms, and Academic Performance at School. Neurobiology of Learning and Memory, 83, 33-42. https://doi.org/10.1016/j.nlm.2004.06.010 Atkinson, M. (2015). Interpreting the Cantab Cognitive Measures. London, UK: Centre for Longitudinal Studies.

Baddeley, A. D. (2017). Exploring Working Memory: Selected Works of Alan Baddeley. New 
York, US: Routledge.

Baddeley, A. D., \& Lieberman, K. (1980) Spatial Working Memory. In Baddeley, A. D. (2017). Exploring Working Memory: Selected Works of Alan Baddeley. New York, US: Routledge.

Blanken, L. M. E., White, T., Mous, S. E., Basten, M., Muetzel, R. L., Jaddoe, V. W. V., Wals, M., van der Ende, J., Verhulst, F. C., \& Tiemeier, H. (2017). Cognitive Functioning in Children with Internalising, Externalising and Dysregulation Problems: A PopulationBased Study. European Child \& Adolescent Psychiatry, 26(4), 445-456. https://doi.org/10.1007/s00787-016-0903-9

Blasiman, R. N., \& Was, C. A. (2018). Why Is Working Memory Performance Unstable? A Review of 21 Factors. Europe's Journal of Psychology, 14(1), 188-231. https://doi.org/10.5964/ejop.v14i1.1472

Brocki, K. C., Nyberg, L., Thorell, L. B., \& Bohlin, G. (2007). Early Concurrent and Longitudinal Symptoms of Adhd and Odd: Relations to Different Types of Inhibitory Control and Working Memory. Journal of Child Psychology and Psychiatry, 48(10), 1033-1041. https://doi.org/10.1111/j.1469-7610.2007.01811.x

Capaldi, D. M., Pears, K. C., Kerr, D. C. R., Owen, L. D., \& Kim, H. K. (2012). Growth in Externalizing and Internalizing Problems in Childhood: A Prospective Study of Psychopathology Across Three Generations. Child Development, 83(6), 1945-1959.

Christopher, G., \& MacDonald, J. (2005). The Impact of Clinical Depression on Working Memory. Cognitive Neuropsychiatry, 10(5), 379-399. https://doi.org/10.1080/13546800444000128

CLS | Millennium Cohort Study. (n.d.). Retrieved 12 May 2020, from https://cls.ucl.ac.uk/clsstudies/millennium-cohort-study/

Connelly, R., \& Platt, L. (2014). Cohort Profile: UK Millennium Cohort Study (MCS). International Journal of Epidemiology, 43(6), 1719-1725. https://doi.org/10.1093/ije/dyu001

Cummings, E. M., \& Davies, P. T. (1994). Maternal Depression and Child Development. Journal of Child Psychology and Psychiatry, 35(1), 73-122. https://doi.org/10.1111/j.1469-7610.1994.tb01133.x

Dekker, M. C., Ferdinand, R. F., Lang, N. D. J. V., Bongers, I. L., Ende, J. V. D., \& Verhulst, F. C. (2007). Developmental Trajectories of Depressive Symptoms from Early Childhood to Late Adolescence: Gender Differences and Adult Outcome. Journal of Child Psychology and Psychiatry, 48(7), 657-666. https://doi.org/10.1111/j.14697610.2007.01742.x

Elliott, C., Smith, P., \& McCullock, K. (1996). British Ability Scales Second Edition (BAS II). Administration and Scoring Manual. London, UK: Nelson

Fanti, K. A. (2010). Trajectories of Pure and Co-Occurring Internalizing and Externalizing Problems from Age 2 to Age 12: Findings from the NICHD Study of Early Child Care. 46(5), 1159-1175.

Ferrin, M., \& Vance, A. (2012). Examination of Neurological Subtle Signs in Adhd as a Clinical Tool for the Diagnosis and Their Relationship to Spatial Working Memory. Journal of Child Psychology and Psychiatry, 53(4), 390-400. https://doi.org/10.1111/j.1469-7610.2011.02496.x

Flouri, E., Papachristou, E., Midouhas, E., Joshi, H., Ploubidis, G. B., \& Lewis, G. (2018). Early Adolescent Outcomes of Joint Developmental Trajectories of Problem Behavior and Iq in Childhood. European Child \& Adolescent Psychiatry, 27(12), 1595-1605. https://doi.org/10.1007/s00787-018-1155-7

Frank, K. A. (2000). Impact of a Confounding Variable on a Regression Coefficient. Sociological Methods \& Research, 29(2), 147-194. 
https://doi.org/10.1177/0049124100029002001

Franke, B., Michelini, G., Asherson, P., Banaschewski, T., Bilbow, A., Buitelaar, J. K., Cormand, B., Faraone, S. V., Ginsberg, Y., Haavik, J., Kuntsi, J., Larsson, H., Lesch, K.P., Ramos-Quiroga, J. A., Réthelyi, J. M., Ribases, M., \& Reif, A. (2018). Live fast, die young? A review on the developmental trajectories of ADHD across the lifespan.

European Neuropsychopharmacology, 28(10), 1059-1088.

https://doi.org/10.1016/j.euroneuro.2018.08.001

Goodman, R. (1997). The Strengths and Difficulties Questionnaire: A Research Note. Journal of Child Psychology and Psychiatry, 38(5), 581-586. https://doi.org/10.1111/j.1469-7610.1997.tb01545.x

Greenwald, R., \& Carr, R. (2018). Working Memory in Children: Effects of Anxiety and Depression. International Journal of School and Cognitive Psychology, 05(03). https://doi.org/10.4172/2469-9837.1000211

Griffith, S. F., Arnold, D. H., Rolon-Arroyo, B., \& Harvey, E. A. (2019). Neuropsychological predictors of ODD symptom dimensions in young children. Journal of Clinical Child \& Adolescent Psychology, 48(1), 80-92.

Gutman, L. M., Joshi, H., \& Schoon, I. (2019). Developmental Trajectories of Conduct Problems and Cumulative Risk from Early Childhood to Adolescence. Journal of Youth and Adolescence, 48(2), 181-198. https://doi.org/10.1007/s10964-018-0971-x

Hansen, K., Johnson, J., Calderwood, L., Mostafa, T., Platt, L., Rosenberg, R., Smith, K., \& The Millinnium Cohort Team. (2014). Millennium Cohort Study, A Guide to the Datasets (Eighth Edition) First, Second, Third, Fourth and Fifth Surveys. London, UK: Centre for Longitudinal Studies.

Hickson, R. P., Annis, I. E., Killeya-Jones, L. A., \& Fang, G. (2020). Opening the black box of the group-based trajectory modeling process to analyze medication adherence patterns: An example using real-world statin adherence data. Pharmacoepidemiology and Drug Safety, 29(3), 357-362. https://doi.org/10.1002/pds.4917

Hughes, C., Roman, G., Hart, M. J., \& Ensor, R. (2013). Does Maternal Depression Predict Young Children's Executive Function? - A 4-Year Longitudinal Study. Journal of Child Psychology and Psychiatry, 54(2), 169-177. https://doi.org/10.1111/jcpp.12014

Jakobsen, J. C., Gluud, C., Wetterslev, J., \& Winkel, P. (2017). When and how should multiple imputation be used for handling missing data in randomised clinical trials $-\mathrm{a}$ practical guide with flowcharts. BMC Medical Research Methodology, 17(1), 162-172. https://doi.org/10.1186/s12874-017-0442-1

Jones, B. L., \& Nagin, D. S. (2012). A Stata Plugin for Estimating Group-Based Trajectory Models. Research Showcase@ CMU. Carnegie Mellon University. Retrieved on July, 10, 2015.

Jones, E. M., \& Ketende, S. C. (2010). User Guide to Analysing MCS Data Using SPSS (p. 35). London, UK: Centre for Longitudinal Studies.

Joshi, H., \& Fitzsimons, E. (2016). The Millennium Cohort Study: The Making of a MultiPurpose Resource for Social Science and Policy. Longitudinal and Life Course Studies, 7(4), 409-430. https://doi.org/10.14301/llcs.v7i4.410

Kessler, R. C., Barker, P. R., Colpe, L. J., Epstein, J. F., Gfroerer, J. C., Hiripi, E., Howes, M. J., Normand, S.-L. T., Manderscheid, R. W., Walters, E. E., \& Zaslavsky, A. M. (2003). Screening for serious mental illness in the general population. Archives of General Psychiatry, 60(2), 184-189. https://doi.org/10.1001/archpsyc.60.2.184

Ketende, S. C., \& Jones, E. M. (2011). User Guide to Analysing MCS Data Using STATA (p. 32). London, UK: Centre for Longitudinal Studies.

King, K. M., Littlefield, A. K., McCabe, C. J., Mills, K. L., Flournoy, J., \& Chassin, L. (2018). Longitudinal modeling in developmental neuroimaging research: Common 
challenges, and solutions from developmental psychology. Developmental Cognitive Neuroscience, 33, 54-72. https://doi.org/10.1016/j.dcn.2017.11.009

Korhonen, M., Luoma, I., Salmelin, R., Siirtola, A., \& Puura, K. (2018). The Trajectories of Internalizing and Externalizing Problems from Early Childhood to Adolescence and Young Adult Outcome. Journal of Child and Adolescent Psychiatry, 2(3). 7-12.

Leve, L. D., Kim, H. K., \& Pears, K. C. (2005). Childhood Temperament and Family Environment as Predictors of Internalizing and Externalizing Trajectories from Age 5 to Age 17. Journal of Abnormal Child Psychology, 33(5), 505-520. https://doi.org/10.1007/s10802-005-6734-7

Logie, R. H. (2009). Visuo-Spatial Working Memory (Nachdr.). London, UK: Psychology Press.

Lui, M., \& Tannock, R. (2007). Working Memory and Inattentive Behaviour in a Community Sample of Children. Behavioral and Brain Functions, 3(1), 12. https://doi.org/10.1186/1744-9081-3-12

Lukasik, K. M., Waris, O., Soveri, A., Lehtonen, M., \& Laine, M. (2019). The Relationship of Anxiety and Stress With Working Memory Performance in a Large Non-depressed Sample. Frontiers in Psychology, 10. https://doi.org/10.3389/fpsyg.2019.00004

Martin, M. J., Davies, P. T., Cummings, E. M., \& Cicchetti, D. (2017). The Mediating Roles of Cortisol Reactivity and Executive Functioning Difficulties in the Pathways Between Childhood Histories of Emotional Insecurity and Adolescent School Problems. Development and Psychopathology, 29(4), 1483-1498. https://doi.org/10.1017/S0954579417000402

Martinussen, R., Hayden, J., Hogg-johnson, S., \& Tannock, R. (2005). A Meta-Analysis of Working Memory Impairments in Children With Attention-Deficit/Hyperactivity Disorder. Journal of the American Academy of Child \& Adolescent Psychiatry, 44(4), 377-384. https://doi.org/10.1097/01.chi.0000153228.72591.73

Mesman, J., Bongers, I. L., \& Koot, H. M. (2001). Preschool Developmental Pathways to Preadolescent Internalizing and Externalizing Problems. The Journal of Child Psychology and Psychiatry and Allied Disciplines, 42(5), 679-689.

Mizoguchi, K., Yuzurihara, M., Ishige, A., Sasaki, H., Chui, D.-H., \& Tabira, T. (2000). Chronic Stress Induces Impairment of Spatial Working Memory Because of Prefrontal Dopaminergic Dysfunction. Journal of Neuroscience, 20(4), 1568-1574. https://doi.org/10.1523/JNEUROSCI.20-04-01568.2000

Murphy, B. L., Arnsten, A. F., Goldman-Rakic, P. S., \& Roth, R. H. (1996). Increased Dopamine Turnover in the Prefrontal Cortex Impairs Spatial Working Memory Performance in Rats and Monkeys. Proceedings of the National Academy of Sciences, 93(3), 1325-1329. https://doi.org/10.1073/pnas.93.3.1325

Nagin, D. S., Jones, B. L., Passos, V. L., \& Tremblay, R. E. (2018a). Group-Based MultiTrajectory Modeling. Statistical Methods in Medical Research, 27(7), 2015-2023. https://doi.org/10.1177/0962280216673085

Nagin, D. S., Jones, B. L., Passos, V. L., \& Tremblay, R. E. (2018b). Group-Based MultiTrajectory Modeling. Statistical Methods in Medical Research, 27(7), 2015-2023. https://doi.org/10.1177/0962280216673085

Nagin, D. S., \& Odgers, C. L. (2010). Group-Based Trajectory Modeling in Clinical Research. Annual Review of Clinical Psychology, 6(1), 109-138. https://doi.org/10.1146/annurev.clinpsy.121208.131413

Nagin, Daniel. (2005). Group-Based Modeling of Development. Cambridge, Massachusetts, US: Harvard University Press. http://dx.doi.org/10.4159/9780674041318

Nivard, M. G., Lubke, G. H., Dolan, C. V., Evans, D. M., St. Pourcain, B., Munafò, M. R., \& Middeldorp, C. M. (2017). Joint Developmental Trajectories of Internalizing and 
Externalizing Disorders Between Childhood and Adolescence. Development and Psychopathology, 29(3), 919-928. https://doi.org/10.1017/S0954579416000572

Nylund-Gibson, K., \& Choi, A. Y. (2018). Ten frequently asked questions about latent class analysis. Translational Issues in Psychological Science, 4(4), 440-461.

https://doi.org/10.1037/tps0000176

Olson, S. L., Choe, D. E., \& Sameroff, A. J. (2017). Trajectories of Child Externalizing Problems Between Ages 3 and 10 Years: Contributions of Children's Early Effortful Control, Theory of Mind, and Parenting Experiences. Development and Psychopathology, 29(4), 1333-1351. https://doi.org/10.1017/S095457941700030X

Oosterlaan, J., Scheres, A., \& Sergeant, J. A. (2005). Which executive functioning deficits are associated with $\mathrm{AD} / \mathrm{HD}, \mathrm{ODD} / \mathrm{CD}$ and comorbid AD/HD+ ODD/CD?. Journal of abnormal child psychology, 33(1), 69-85.

Parkes, A., Sweeting, H., \& Wight, D. (2016). Early Childhood Precursors and School age Correlates of Different Internalising Problem Trajectories Among Young Children. Journal of Abnormal Child Psychology, 44(7), 1333- 1346. https://doi.org/10.1007/s10802-015-0116-6

Raftery, A. E. (1995). Bayesian Model Selection in Social Research. Sociological Methodology, 25, 111-163. JSTOR. https://doi.org/10.2307/271063

Robbins, T. W., James, M., Owen, A. M., Sahakian, B. J., McInnes, L., \& Rabbitt, P. (1994). Cambridge Neuropsychological Test Automated Battery (CANTAB): A factor analytic study of a large sample of normal elderly volunteers. Dementia (Basel, Switzerland), 5(5), 266-281. https://doi.org/10.1159/000106735

Royston, P. (2004). Multiple Imputation of Missing Values. The Stata Journal, 4(3), 227241. https://doi.org/10.1177/1536867X0400400301

Ruttle, P. L., Shirtcliff, E. A., Serbin, L. A., Ben-Dat Fisher, D., Stack, D. M., \& Schwartzman, A. E. (2011). Disentangling Psychobiological Mechanisms Underlying Internalizing and Externalizing Behaviors in Youth: Longitudinal and Concurrent Associations with Cortisol. Hormones and Behavior, 59(1), 123-132. https://doi.org/10.1016/j.yhbeh.2010.10.015

Saarinen, S., Fontell, T., Vuontela, V., Carlson, S., \& Aronen, E. T. (2015). Visuospatial Working Memory in 7- to 12-Year-Old Children with Disruptive Behavior Disorders. Child Psychiatry \& Human Development, 46(1), 34-43. https://doi.org/10.1007/s10578014-0449-3

Schoemaker, K., Mulder, H., Deković, M., \& Matthys, W. (2013). Executive Functions in Preschool Children with Externalizing Behavior Problems: A Meta-Analysis. Journal of Abnormal Child Psychology, 41(3), 457-471. https://doi.org/10.1007/s10802-012-9684-x

Shackman, A. J., Sarinopoulos, I., Maxwell, J. S., Pizzagalli, D. A., Lavric, A., \& Davidson, R. J. (2006). Anxiety Selectively Disrupts Visuospatial Working Memory. Emotion, 6(1), 40-61. https://doi.org/10.1037/1528-3542.6.1.40

Soltanlou, M., Artemenko, C., Dresler, T., Fallgatter, A. J., Ehlis, A.-C., \& Nuerk, H.-C. (2019). Math Anxiety in Combination With Low Visuospatial Memory Impairs Math Learning in Children. Frontiers in psychology, 10, 89. https://doi.org/10.1016/j.nlm.2004.06.010

Sterba, S. K., Prinstein, M. J., \& Cox, M. J. (2007). Trajectories of Internalizing Problems Across Childhood: Heterogeneity, External Validity, and Gender Differences.

Development and Psychopathology, 19(2), 345-366. https://doi.org/10.1017/S0954579407070174

Taverniers, J., Ruysseveldt, J. V., Smeets, T., \& Grumbkow, J. von. (2010). High-Intensity Stress Elicits Robust Cortisol Increases, and Impairs Working Memory and Visuo-Spatial Declarative Memory in Special Forces Candidates: A Field Experiment. Stress, 13(4), 
324-334. https://doi.org/10.3109/10253891003642394

Thorell, L. B., \& Wåhlstedt, C. (2006). Executive functioning deficits in relation to symptoms of ADHD and/or ODD in preschool children. Infant and Child Development, 15(5), 503-518.

Voyer, D., Voyer, S. D., \& Saint-Aubin, J. (2017). Sex Differences in Visual-Spatial Working Memory: A Meta-Analysis. Psychonomic Bulletin \& Review, 24(2), 307-334. https://doi.org/10.3758/s13423-016-1085-7

Wåhlstedt, C., Thorell, L. B., \& Bohlin, G. (2008). ADHD Symptoms and Executive Function Impairment: Early Predictors of Later Behavioral Problems. Developmental Neuropsychology, 33(2), 160-178. https://doi.org/10.1080/87565640701884253

Willcutt, E. G., Doyle, A. E., Nigg, J. T., Faraone, S. V., \& Pennington, B. F. (2005). Validity of the Executive Function Theory of Attention-Deficit/Hyperactivity Disorder: A Meta-Analytic Review. Biological Psychiatry, 57(11), 1336-1346. https://doi.org/10.1016/j.biopsych.2005.02.006

Zahrt, J., Taylor, J. R., Mathew, R. G., \& Arnsten, A. F. T. (1997). Supranormal Stimulation of D1 Dopamine Receptors in the Rodent Prefrontal Cortex Impairs Spatial Working Memory Performance. Journal of Neuroscience, 17(21), 8528-8535. https://doi.org/10.1523/JNEUROSCI.17-21-08528.1997 
Table 1.1 summarizes the tetrachoric correlations (Spearman's ranks) and descriptive statistics of internalising problems, conduct problems and hyperactivity/inattention at children's ages 3, 5, 7 and 11 years.

Table 1.2 summarizes the pairwise Pearson correlations and descriptive statistics of SWM total errors and SWM strategy at children's age 11 years.

Tables 2.1/2.2/2.3 show distribution of variables by trajectory group of internalising problems, conduct problems and hyperactivity-inattention

Tables 3/5/7 Multiple regression models predicting SWM (total errors)

Tables 4/6/8 Multiple regression models predicting SWM (strategy) 
Table 1.1 Tetrachoric correlations and descriptive statistics of internalising problems, conduct problems and hyperactivity/inattention (unweighted data)

\begin{tabular}{|c|c|c|c|c|c|c|c|c|c|c|c|c|c|}
\hline & 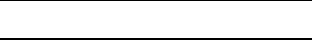 & 1 & 2 & 3 & 4 & 5 & 6 & 7 & 8 & 9 & 10 & 11 & 12 \\
\hline 1. & $\begin{array}{l}\text { Internalising problems, } \\
\text { age } 3\end{array}$ & 1.00 & & & & & & & & & & & \\
\hline 2. & $\begin{array}{l}\text { Internalising problems, } \\
\text { age } 5\end{array}$ & $0.50 * *$ & 1.00 & & & & & & & & & & \\
\hline 3. & $\begin{array}{l}\text { Internalising problems, } \\
\text { age } 7\end{array}$ & $0.44 * *$ & $0.63 * *$ & 1.00 & & & & & & & & & \\
\hline 4. & $\begin{array}{l}\text { Internalising problems, } \\
\text { age } 11\end{array}$ & $0.36 * *$ & $0.48 * *$ & $0.59 * *$ & 1.00 & & & & & & & & \\
\hline 5. & $\begin{array}{l}\text { Conduct problems, age } \\
3\end{array}$ & $0.33 * *$ & $0.27 * *$ & $0.27 * *$ & $0.28 * *$ & 1.00 & & & & & & & \\
\hline 6. & $\begin{array}{l}\text { Conduct problems, age } \\
5\end{array}$ & $0.30 * *$ & $0.44 * *$ & $0.39 * *$ & $0.34 * *$ & $0.54 * *$ & 1.00 & & & & & & \\
\hline 7. & $\begin{array}{l}\text { Conduct problems, age } \\
7\end{array}$ & $0.24 * *$ & $0.36 * *$ & $0.48 * *$ & $0.39^{* *}$ & $0.47 * *$ & $0.67 * *$ & 1.00 & & & & & \\
\hline 8. & $\begin{array}{l}\text { Conduct problems, age } \\
11\end{array}$ & $0.24 * *$ & $0.31 * *$ & $0.35 * *$ & $0.49 * *$ & $0.43 * *$ & $0.57 * *$ & $0.66 * *$ & 1.00 & & & & \\
\hline 9. & $\begin{array}{l}\text { Hyperactivity/inattenti } \\
\text { on, age } 3\end{array}$ & $0.34 * *$ & $0.32 * *$ & $0.32 * *$ & $0.29 * *$ & $0.50 * *$ & $0.40 * *$ & $0.43 * *$ & $0.35^{* *}$ & 1.00 & & & \\
\hline 10. & $\begin{array}{l}\text { Hyperactivity/inattenti } \\
\text { on, age } 5\end{array}$ & $0.30 * *$ & $0.41 * *$ & $0.39 * *$ & $0.36^{* *}$ & $0.42 * *$ & $0.59 * *$ & $0.53 * *$ & $0.46^{* *}$ & $0.64 * *$ & 1.00 & & \\
\hline & $\begin{array}{l}\text { Hyperactivity/inattenti } \\
\text { on, age } 7\end{array}$ & $0.27 * *$ & $0.36 * *$ & $0.45 * *$ & $0.40 * *$ & $0.37 * *$ & $0.50 * *$ & $0.63 * *$ & $0.49 * *$ & $0.56 * *$ & $0.73 * *$ & 1.00 & \\
\hline & $\begin{array}{l}\text { Hyperactivity/inattenti } \\
\text { on, age } 11\end{array}$ & $0.24 * *$ & $0.32 * *$ & $0.42 * *$ & $0.51 * *$ & $0.37 * *$ & $0.47 * *$ & $0.53 * *$ & $0.65 * *$ & $0.49 * *$ & $0.62 * *$ & $0.74 * *$ & 1.00 \\
\hline Nor & mal: $\quad \mathrm{N}$ & 10,443 & 11,523 & 10,166 & 9,049 & 7,297 & 11,574 & 10,843 & 10,269 & 11,245 & 12,261 & 10,955 & 10,666 \\
\hline At & isk: & 4,412 & 3,401 & 3,465 & 3,808 & 7,668 & 3,373 & 2,807 & 2,591 & 3,706 & 2,682 & 2,698 & 2,198 \\
\hline Tot & $\mathrm{N}$ & 14,855 & 14,924 & 13,631 & 12,857 & 14,965 & 14,947 & 13,650 & 12,860 & 14,951 & 14,943 & 13,653 & 12,864 \\
\hline
\end{tabular}

Note: $* \mathrm{p}<0.05 * * \mathrm{p}<0.01$ 
Table 1.2 Pairwise Pearson correlations and descriptive statistics of SWM total errors and SWM strategy at age 11 (unweighted data)

\begin{tabular}{lll}
\hline & SWM total errors & SWM strategy \\
\hline SWM total errors & 1.00 & \\
SWM strategy & $0.65^{*}$ & 1.00 \\
Mean $(S D)$ & $35.71(18.76)$ & $34.32(5.94)$ \\
$N$ & 12,757 & 12,757 \\
\hline
\end{tabular}

Note: $* \mathrm{p}<0.05$ 
Table 2.1 Distribution of variables by trajectory group of internalising problems (unweighted data)

\begin{tabular}{|c|c|c|c|c|c|c|c|c|}
\hline & $\begin{array}{c}\text { Total } \\
\mathrm{N}=12,589 \\
\end{array}$ & Range & $\begin{array}{l}1 . \text { No risk } \\
\mathrm{N}=5,300\end{array}$ & $\begin{array}{l}\text { 2. Deteriorating } \\
\qquad \mathrm{N}=738\end{array}$ & $\begin{array}{c}\text { 3. Low risk } \\
\mathrm{N}=3,411\end{array}$ & $\begin{array}{l}\text { 4. High risk } \\
\mathrm{N}=1,880\end{array}$ & $\mathrm{p}$-value & Effect size \\
\hline \multicolumn{8}{|c|}{ Continuous variables, $M(S D)$} & Eta-Squared \\
\hline SWM errors & $35.27(18.65)$ & {$[0,173]$} & $32.95(18.03)$ & $37.71(18.00)$ & $35.77(18.71)$ & $39.96(19.45)$ & $<0.001$ & .02 \\
\hline SWM strategy & $34.22(5.90)$ & {$[0,48]$} & $33.78(5.78)$ & $34.76(5.81)$ & $34.37(5.86)$ & $34.95(6.27)$ & $<0.001$ & .01 \\
\hline Age in months & $133.44(3.99)$ & {$[120,147.96]$} & $133.49(3.95)$ & $131.99(4.21)$ & $133.69(3.90)$ & $133.41(4.02)$ & $<0.001$ & .01 \\
\hline Poverty & $0.27(0.36)$ & {$[0,1]$} & $0.18(0.31)$ & $0.29(0.36)$ & $0.31(0.38)$ & $0.45(0.40)$ & $<0.001$ & .07 \\
\hline $\begin{array}{l}\text { Maternal } \\
\text { depression }\end{array}$ & $0.21(0.31)$ & {$[0,1]$} & $0.12(0.24)$ & $0.27(0.33)$ & $0.24(0.32)$ & $0.41(0.38)$ & $<0.001$ & .11 \\
\hline Verbal ability & $58.89(9.85)$ & {$[20,80]$} & $60.46(8.95)$ & $58.71(10.33)$ & $58.31(9.81)$ & $55.59(11.14)$ & $<0.001$ & .03 \\
\hline \multicolumn{8}{|c|}{ Categorical variables, $n(\%)$} & Cramer's $V$ \\
\hline Female & $5,661(50 \%)$ & 1 & $2,710(51 \%)$ & $370(50 \%)$ & $1,700(50 \%)$ & $881(47 \%)$ & 0.017 & .03 \\
\hline Mixed & $300(3 \%)$ & 1 & $121(2 \%)$ & $29(4 \%)$ & $80(2 \%)$ & $70(4 \%)$ & $<0.001$ & .04 \\
\hline Indian & $266(2 \%)$ & 1 & $84(2 \%)$ & $13(2 \%)$ & $102(3 \%)$ & $67(4 \%)$ & $<0.001$ & .05 \\
\hline $\begin{array}{l}\text { Pakistani and } \\
\text { Bangladeshi }\end{array}$ & $671(6 \%)$ & 1 & $150(3 \%)$ & $20(3 \%)$ & $262(8 \%)$ & $239(13 \%)$ & $<0.001$ & .16 \\
\hline $\begin{array}{l}\text { Black or Black } \\
\text { British }\end{array}$ & $301(3 \%)$ & 1 & $134(3 \%)$ & $9(1 \%)$ & $107(3 \%)$ & $51(3 \%)$ & $<0.001$ & .03 \\
\hline $\begin{array}{l}\text { Other (Inc } \\
\text { Chinese) }\end{array}$ & $141(1 \%)$ & 1 & $40(1 \%)$ & $8(1 \%)$ & $61(2 \%)$ & $32(2 \%)$ & $<0.001$ & .04 \\
\hline $\begin{array}{l}\text { Mother has } 1^{\text {st }} \\
\text { degree }\end{array}$ & $2,109(19 \%)$ & 1 & $1,276(25 \%)$ & $108(15 \%)$ & $534(16 \%)$ & $191(11 \%)$ & $<0.001$ & .14 \\
\hline
\end{tabular}

degree

p-values for between group F-tests for continuous variables and chi-square tests for categorical variables

Effect size: Eta-Squared for continuous variables and Cramer's V for categorical variables 
Table 2.2 Distribution of variables by trajectory group of conduct problems (unweighted data)

\begin{tabular}{|c|c|c|c|c|c|c|c|c|}
\hline & $\begin{array}{c}\text { Total } \\
\mathrm{N}=12,589\end{array}$ & Range & $\begin{array}{l}\text { 1. Deteriorating } \\
\mathrm{N}=353\end{array}$ & $\begin{array}{c}\text { 2. Early childhood } \\
\text { limited } \\
\mathrm{N}=7,249\end{array}$ & $\begin{array}{l}\text { 3. Improving } \\
\mathrm{N}=2,300\end{array}$ & $\begin{array}{l}\text { 4. High risk } \\
\mathrm{N}=1,348\end{array}$ & $\mathrm{p}$-value & Effect size \\
\hline \multicolumn{8}{|c|}{ Continuous variables, $M(S D)$} & Eta-Squared \\
\hline SWM errors & $35.27(18.65)$ & {$[0,173]$} & $36.06(17.52)$ & $33.55(18.41)$ & $37.51(18.96)$ & $40.51(18.36)$ & $<0.001$ & .02 \\
\hline SWM strategy & $34.21(5.91)$ & {$[0,48]$} & $34.65(5.37)$ & $33.86(5.96)$ & $34.63(5.80)$ & $35.29(5.76)$ & $<0.001$ & .01 \\
\hline Age in months & $133.44(3.98)$ & {$[120,147.96]$} & $132.35(3.70)$ & $133.52(3.96)$ & $133.59(4.09)$ & $133.09(3.96)$ & $<0.001$ & .00 \\
\hline Poverty & $0.27(0.36)$ & {$[0,1]$} & $0.27(0.35)$ & $0.21(0.33)$ & $0.37(0.39)$ & $0.45(0.40)$ & $<0.001$ & .06 \\
\hline $\begin{array}{l}\text { Maternal } \\
\text { depression }\end{array}$ & $0.21(0.31)$ & {$[0,1]$} & $0.21(0.31)$ & $0.15(0.27)$ & $0.29(0.34)$ & $0.40(0.38)$ & $<0.001$ & .08 \\
\hline Verbal ability & $58.88(9.86)$ & {$[20,80]$} & $57.35(10.08)$ & $60.13(9.33)$ & $57.31(9.98)$ & $55.19(10.98)$ & $<0.001$ & .03 \\
\hline \multicolumn{8}{|c|}{ Categorical variables, $n(\%)$} & Cramer's V \\
\hline Female & $5,615(50 \%)$ & 1 & $170(48 \%)$ & $3,864(53 \%)$ & $1,071(47 \%)$ & $510(38 \%)$ & $<0.001$ & .10 \\
\hline Mixed & $298(3 \%)$ & 1 & $6(2 \%)$ & $176(2 \%)$ & $67(3 \%)$ & $49(4 \%)$ & $<0.001$ & .03 \\
\hline Indian & $266(2 \%)$ & 1 & $7(2 \%)$ & $166(2 \%)$ & $72(3 \%)$ & $21(2 \%)$ & $<0.001$ & .03 \\
\hline $\begin{array}{l}\text { Pakistani and } \\
\text { Bangladeshi }\end{array}$ & $668(6 \%)$ & 1 & $16(5 \%)$ & $386(5 \%)$ & $188(8 \%)$ & $78(6 \%)$ & $<0.001$ & .05 \\
\hline $\begin{array}{l}\text { Black or Black } \\
\text { British }\end{array}$ & $300(3 \%)$ & 1 & $10(3 \%)$ & $196(3 \%)$ & $70(3 \%)$ & $24(2 \%)$ & $<0.001$ & .02 \\
\hline $\begin{array}{l}\text { Other (Inc } \\
\text { Chinese) }\end{array}$ & $140(1 \%)$ & 1 & $5(1 \%)$ & $87(1 \%)$ & $29(1 \%)$ & $19(1 \%)$ & $<0.001$ & .01 \\
\hline $\begin{array}{l}\text { Mother has } 1^{\text {st }} \\
\text { degree }\end{array}$ & $2,093(19 \%)$ & 1 & $59(17 \%)$ & $1,643(23 \%)$ & $278(13 \%)$ & $113(9 \%)$ & $<0.001$ & .15 \\
\hline
\end{tabular}

Total number includes 1,339 individuals with missing value on group membership.

p-values for between group F-tests for continuous variables and chi-square tests for categorical variables

Effect size: Eta-Squared for continuous variables and Cramer's V for categorical variables 
Table 2.3 Distribution of variables by trajectory group of hyperactivity/inattention (unweighted data)

\begin{tabular}{|c|c|c|c|c|c|c|c|c|}
\hline & $\begin{array}{c}\text { Total } \\
\mathrm{N}=12,589\end{array}$ & Range & $\begin{array}{l}\text { 1. Deteriorating } \\
\mathrm{N}=1,007\end{array}$ & $\begin{array}{l}\text { 2. Improving } \\
\mathrm{N}=1,629\end{array}$ & $\begin{array}{c}\text { 3. Typically } \\
\text { developing } \\
\mathrm{N}=7,939\end{array}$ & $\begin{array}{l}\text { 4. High risk } \\
\mathrm{N}=756\end{array}$ & $\mathrm{p}$-value & Effect size \\
\hline \multicolumn{8}{|c|}{ Continuous variables, $M(S D)$} & Eta-Squared \\
\hline SWM errors & $35.27(18.65)$ & {$[0,173]$} & $39.20(18.27)$ & $39.04(18.50)$ & $33.17(18.30)$ & $43.99(18.55)$ & $<0.001$ & .03 \\
\hline SWM strategy & $34.22(5.90)$ & {$[0,48]$} & $34.88(5.66)$ & $35.13(5.43)$ & $33.79(6.00)$ & $35.82(5.65)$ & $<0.001$ & .01 \\
\hline Age in months & $133.44(3.99)$ & {$[120,147.96]$} & $133.06(4.02)$ & $133.47(3.97)$ & $133.50(3.96)$ & $133.25(4.17)$ & 0.005 & .00 \\
\hline Poverty & $0.27(0.36)$ & {$[0,1]$} & $0.33(0.38)$ & $0.41(0.40)$ & $0.22(0.34)$ & $0.42(0.39)$ & $<0.001$ & .05 \\
\hline $\begin{array}{l}\text { Maternal } \\
\text { depression }\end{array}$ & $0.21(0.31)$ & {$[0,1]$} & $0.28(0.34)$ & $0.33(0.36)$ & $0.16(0.28)$ & $0.42(0.38)$ & $<0.001$ & .07 \\
\hline Verbal ability & $58.89(9.85)$ & {$[20,80]$} & $56.87(10.15)$ & $56.23(10.24)$ & $60.12(9.22)$ & $54.23(11.91)$ & $<0.001$ & .04 \\
\hline \multicolumn{8}{|c|}{ Categorical variables, $n(\%)$} & Cramer's $V$ \\
\hline Female & $5,660(50 \%)$ & 1 & $427(42 \%)$ & $707(43 \%)$ & $4,309(54 \%)$ & $217(29 \%)$ & $<0.001$ & .15 \\
\hline Mixed & $300(3 \%)$ & 1 & $24(2 \%)$ & $54(3 \%)$ & $199(3 \%)$ & $23(3 \%)$ & $<0.001$ & .02 \\
\hline Indian & $266(2 \%)$ & 1 & $20(2 \%)$ & $54(3 \%)$ & $178(2 \%)$ & $14(2 \%)$ & $<0.001$ & .03 \\
\hline \multicolumn{9}{|l|}{ Bangladeshi } \\
\hline \multicolumn{8}{|l|}{ British } & .02 \\
\hline \multicolumn{9}{|l|}{ Chinese) } \\
\hline $\begin{array}{l}\text { Mother has } 1^{\text {st }} \\
\text { degree }\end{array}$ & $2,109(19 \%)$ & 1 & $136(14 \%)$ & $154(10 \%)$ & $1,761(23 \%)$ & $58(8 \%)$ & $<0.001$ & .14 \\
\hline
\end{tabular}

Total number includes 1,258 individuals with missing value on group membership.

p-values for between group F-tests for continuous variables and chi-square tests for categorical variables

Effect size: Eta-Squared for continuous variables and Cramer's V for categorical variables 
Table 3 Regression estimates [coefficients (SE)] of internalising problem group membership on SWM total errors

\begin{tabular}{|c|c|c|c|c|}
\hline & Model 1 & Model 2 & Model 3 & Model 4 \\
\hline \multicolumn{5}{|l|}{ Internalising } \\
\hline \multicolumn{5}{|l|}{$\begin{array}{l}\text { Behaviours (Ref: } \\
\text { No risk) }\end{array}$} \\
\hline Deteriorating & $4.69(0.89) * * *$ & $4.23(0.89) * * *$ & $3.09(0.89) * * *$ & $2.60(0.92) * *$ \\
\hline Low risk & $3.14(0.51) * * *$ & $3.19(0.51) * * *$ & $1.76(0.50) * * *$ & $1.33(0.50) * *$ \\
\hline High risk & $7.15(0.56) * * *$ & $7.03(0.55) * * *$ & $4.30(0.62) * * *$ & $3.09(0.60) * * *$ \\
\hline Age at Sweep 5 & & $-0.31(0.06) * * *$ & $-0.32(0.06) * * *$ & $-0.35(0.05) * * *$ \\
\hline \multicolumn{5}{|l|}{ Gender (Ref: } \\
\hline \multicolumn{5}{|l|}{ Male) } \\
\hline Female & & $-1.10(0.39) * *$ & $-1.16(0.37) * *$ & $-1.33(0.37) * * *$ \\
\hline Poverty & & & $6.14(0.63) * * *$ & $4.58(0.66) * * *$ \\
\hline \multicolumn{5}{|l|}{ Ethnicity (Ref: } \\
\hline \multicolumn{5}{|l|}{ White) } \\
\hline Mixed & & & $0.76(1.38)$ & $1.23(1.37)$ \\
\hline Indian & & & $-0.02(1.57)$ & $0.98(1.62)$ \\
\hline Pakistani and & & & $0.86(0.92)$ & $0.42(1.06)$ \\
\hline \multicolumn{5}{|l|}{ Bangladeshi } \\
\hline Black or Black & & & $5.48(1.54) * * *$ & $6.23(1.48) * * *$ \\
\hline \multicolumn{5}{|l|}{ British } \\
\hline Other (Inc & & & $-2.70(1.74)$ & $-2.31(1.76)$ \\
\hline \multicolumn{5}{|l|}{ Chinese) } \\
\hline \multicolumn{5}{|l|}{ Maternal } \\
\hline \multicolumn{5}{|l|}{ Education } \\
\hline Has $1^{\text {st }}$ degree & & & $-6.10(0.54) * * *$ & $-4.85(0.56) * * *$ \\
\hline Maternal & & & $1.00(0.79)$ & $1.09(0.76)$ \\
\hline \multicolumn{5}{|l|}{ Depression } \\
\hline Verbal ability & & & & $-0.32(0.02) * * *$ \\
\hline Constant & $33.15(0.33) * * *$ & $74.96(7.57) * * *$ & $76.31(7.43)$ *** & $98.75(6.97)$ *** \\
\hline
\end{tabular}

Model 1: Group membership of problem behaviours

Model 2: Model $1+$ Age + Gender

Model 3: Model $2+$ Poverty + Ethnicity + Maternal Education + Maternal Depression

Model 4: Model $3+$ Verbal Ability (Verbal Similarities at age 11) 
Table 4 Regression estimates [coefficients (SE)] of internalising problem group membership on SWM strategy

\begin{tabular}{|c|c|c|c|c|}
\hline & Model 1 & Model 2 & Model 3 & Model 4 \\
\hline \multicolumn{5}{|l|}{ Internalising } \\
\hline \multicolumn{5}{|l|}{ Behaviours (Ref: } \\
\hline \multicolumn{5}{|l|}{ No risk) } \\
\hline Deteriorating & $0.81(0.30) * *$ & $0.73(0.30) *$ & $0.45(0.30)$ & $0.36(0.30)$ \\
\hline Low risk & $0.69(0.15) * * *$ & $0.71(0.15) * * *$ & $0.37(0.15) *$ & $0.29(0.15)$ \\
\hline High risk & $1.13(0.19)$ *** & $1.13(0.19) * * *$ & $0.48(0.19) *$ & $0.29(0.20)$ \\
\hline Age at Sweep 5 & & $-0.06(0.02) * * *$ & $-0.06(0.02) * * *$ & $-0.09(0.02) * * *$ \\
\hline \multicolumn{5}{|l|}{ Gender (Ref: } \\
\hline \multicolumn{5}{|l|}{ Male) } \\
\hline Female & & $0.13(0.13)$ & $0.12(0.12)$ & $0.06(0.12)$ \\
\hline Poverty & & & $1.08(0.19) * * *$ & $0.69(0.19) * * *$ \\
\hline \multicolumn{5}{|l|}{ Ethnicity (Ref: } \\
\hline \multicolumn{5}{|l|}{ White) } \\
\hline Mixed & & & $0.01(0.38)$ & $0.09(0.38)$ \\
\hline Indian & & & $-0.45(0.53)$ & $-0.19(0.53)$ \\
\hline Pakistani and & & & $0.53(0.29)$ & $0.40(0.31)$ \\
\hline \multicolumn{5}{|l|}{ Bangladeshi } \\
\hline Black or Black & & & $0.88(0.37) *$ & $1.00(0.35) * *$ \\
\hline \multicolumn{5}{|l|}{ British } \\
\hline Other (Inc & & & $-0.79(0.60)$ & $-0.66(0.63)$ \\
\hline \multicolumn{5}{|l|}{ Chinese) } \\
\hline \multicolumn{5}{|l|}{ Maternal } \\
\hline \multicolumn{5}{|l|}{ Education } \\
\hline Has $1^{\text {st }}$ degree & & & $-1.82(0.19) * * *$ & $-1.50(0.21) * * *$ \\
\hline Maternal & & & $0.37(0.22)$ & $0.41(0.21)$ \\
\hline \multicolumn{5}{|l|}{ Depression } \\
\hline Verbal ability & & & & $-0.08(0.01) * * *$ \\
\hline Constant & $33.85(0.10) * * *$ & $41.82(2.34) * * *$ & $42.30(2.30) * * *$ & $50.40(2.24) * * *$ \\
\hline
\end{tabular}
$* \mathrm{p}<0.05 ; * * \mathrm{p}<0.01 ; * * * \mathrm{p}<0.001$

Model 1: Group membership of problem behaviours

Model 2: Model $1+$ Age + Gender

Model 3: Model $2+$ Poverty + Ethnicity + Maternal Education + Maternal Depression

Model 4: Model $3+$ Verbal Ability (Verbal Similarities at age 11) 
Table 5 Regression estimates [coefficients (SE)] of conduct problem group membership on SWM total errors

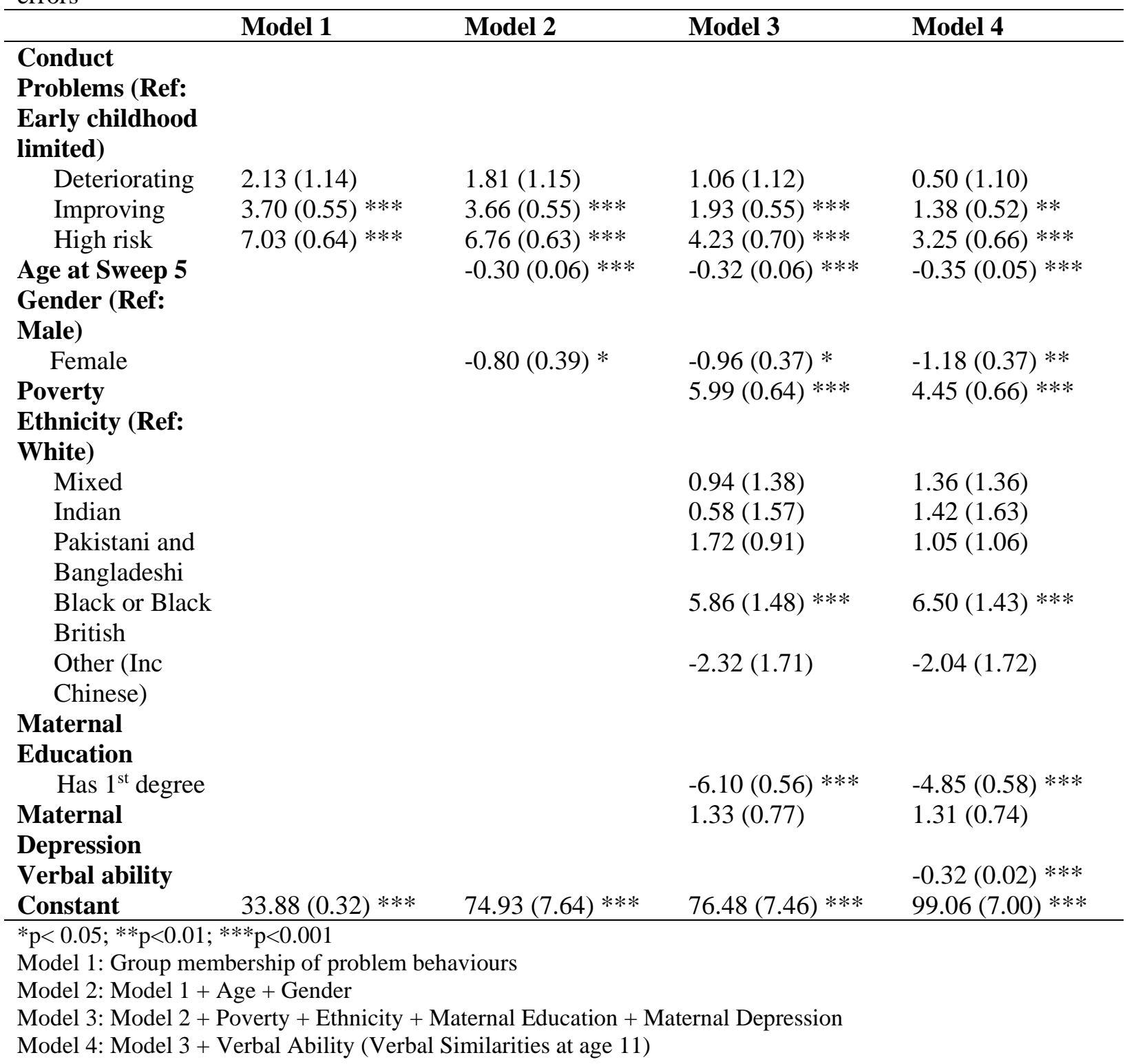


Table 6 Regression estimates [coefficients (SE)] of conduct problem group membership on SWM strategy

\begin{tabular}{|c|c|c|c|c|}
\hline & Model 1 & Model 2 & Model 3 & Model 4 \\
\hline \multicolumn{5}{|l|}{ Conduct } \\
\hline \multicolumn{5}{|l|}{ Problems (Ref: } \\
\hline \multicolumn{5}{|l|}{ Early childhood } \\
\hline \multicolumn{5}{|l|}{ limited) } \\
\hline Deteriorating & $0.89(0.32) * *$ & $0.84(0.32) * *$ & $0.66(0.31) *$ & $0.49(0.30)$ \\
\hline Improving & $0.79(0.17) * * *$ & $0.80(0.17) * * *$ & $0.42(0.17) *$ & $0.33(0.16) *$ \\
\hline High risk & $1.40(0.22) * * *$ & $1.40(0.22) * * *$ & $0.84(0.23) * * *$ & $0.70(0.21) * *$ \\
\hline Age at Sweep 5 & & $-0.06(0.02) * *$ & $-0.06(0.02) * *$ & $-0.09(0.02) * * *$ \\
\hline \multicolumn{5}{|l|}{ Gender (Ref: } \\
\hline \multicolumn{5}{|l|}{ Male) } \\
\hline Female & & $0.20(0.13)$ & $0.17(0.12)$ & $0.11(0.12)$ \\
\hline Poverty & & & $1.01(0.18) * * *$ & $0.62(0.18) * * *$ \\
\hline \multicolumn{5}{|l|}{ Ethnicity (Ref: } \\
\hline \multicolumn{5}{|l|}{ White) } \\
\hline Mixed & & & $0.02(0.38)$ & $0.09(0.38)$ \\
\hline Indian & & & $-0.34(0.53)$ & $-0.11(0.54)$ \\
\hline Pakistani and & & & $0.67(0.29) *$ & $0.51(0.30)$ \\
\hline \multicolumn{5}{|l|}{ Bangladeshi } \\
\hline Black or Black & & & $0.96(0.36) * *$ & $1.06(0.35) * *$ \\
\hline \multicolumn{5}{|l|}{ British } \\
\hline Other (Inc & & & $-0.72(0.61)$ & $-0.60(0.63)$ \\
\hline \multicolumn{5}{|l|}{ Chinese) } \\
\hline \multicolumn{5}{|l|}{ Maternal } \\
\hline \multicolumn{5}{|l|}{ Education } \\
\hline Has $1^{\text {st }}$ degree & & & $-1.82(0.19) * * *$ & $-1.51(0.21) * * *$ \\
\hline Maternal & & & $0.32(0.21)$ & $0.34(0.21)$ \\
\hline \multicolumn{5}{|l|}{ Depression } \\
\hline Verbal ability & & & & $-0.08(0.01) * * *$ \\
\hline Constant & $33.93(0.09) * * *$ & $41.42(2.32) * * *$ & $41.95(2.28) * * *$ & $49.98(2.23) * * *$ \\
\hline
\end{tabular}

*p< $0.05 ; * * \mathrm{p}<0.01 ; * * * \mathrm{p}<0.001$

Model 1: Group membership of problem behaviours

Model 2: Model $1+$ Age + Gender

Model 3: Model $2+$ Poverty + Ethnicity + Maternal Education + Maternal Depression

Model 4: Model $3+$ Verbal Ability (Verbal Similarities at age 11) 
Table 7 Regression estimates [coefficients (SE)] of hyperactivity/inattention group membership on SWM total errors

\begin{tabular}{|c|c|c|c|c|}
\hline & Model 1 & Model 2 & Model 3 & Model 4 \\
\hline \multicolumn{5}{|l|}{$\begin{array}{l}\text { Hyperactivity/inattention } \\
\text { (Ref: Typically } \\
\text { developing) }\end{array}$} \\
\hline Deteriorating & $5.68(0.72) * * *$ & $5.49(0.73) * * *$ & $4.31(0.70) * * *$ & $3.59(0.71) * * *$ \\
\hline Improving & $5.55(0.59) * * *$ & $5.50(0.59) * * *$ & $3.55(0.60) * * *$ & $2.88(0.59) * * *$ \\
\hline High risk & $10.04(0.87) * * *$ & $9.81(0.86) * * *$ & $7.63(0.92) * * *$ & $5.80(0.80) * * *$ \\
\hline Age at Sweep 5 & & $-0.30(0.06) * * *$ & $-0.31(0.05) * * *$ & $-0.34(0.05) * * *$ \\
\hline \multicolumn{5}{|l|}{ Gender (Ref: Male) } \\
\hline Female & & $-0.39(0.39)$ & $-0.59(0.38)$ & $-0.88(0.37) *$ \\
\hline Poverty & & & $5.92(0.62) * * *$ & $4.44(0.65) * * *$ \\
\hline \multicolumn{5}{|l|}{ Ethnicity (Ref: White) } \\
\hline Mixed & & & $0.93(1.38)$ & $1.32(1.36)$ \\
\hline Indian & & & $0.47(1.56)$ & $1.28(1.62)$ \\
\hline Pakistani and & & & $1.53(0.94)$ & $0.92(1.07)$ \\
\hline Bangladeshi & & & & \\
\hline Black or Black British & & & $6.01(1.50) * * *$ & $6.59(1.44) * * *$ \\
\hline Other (Inc Chinese) & & & $-1.94(1.67)$ & $-1.77(1.69)$ \\
\hline \multicolumn{5}{|l|}{ Maternal Education } \\
\hline Has $1^{\text {st }}$ degree & & & $-5.84(0.56) * * *$ & $-4.68(0.58) * * *$ \\
\hline Maternal Depression & & & $0.82(0.76)$ & $0.90(0.74)$ \\
\hline Verbal ability & & & & $-0.31(0.02) * * *$ \\
\hline Constant & $33.55(0.29) * * *$ & $73.70(7.55) * * *$ & $74.78(7.36) * * *$ & $96.65(7.02) * * *$ \\
\hline
\end{tabular}

$* \mathrm{p}<0.05 ; * * \mathrm{p}<0.01 ; * * * \mathrm{p}<0.001$

Model 1: Group membership of problem behaviours

Model 2: Model $1+$ Age + Gender

Model 3: Model $2+$ Poverty + Ethnicity + Maternal Education + Maternal Depression

Model 4: Model $3+$ Verbal Ability (Verbal Similarities at age 11) 
Table 8 Regression estimates [coefficients (SE)] of hyperactivity/inattention group membership on SWM strategy

\begin{tabular}{|c|c|c|c|c|}
\hline 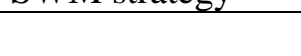 & Model 1 & Model 2 & Model 3 & Model 4 \\
\hline \multirow{2}{*}{\multicolumn{5}{|c|}{$\begin{array}{l}\text { Hyperactivity/ina } \\
\text { ttention (Ref: } \\
\text { Typically } \\
\text { developing) }\end{array}$}} \\
\hline & & & & \\
\hline Deteriorating & $1.10(0.23) * * *$ & $1.10(0.23) * * *$ & $0.82(0.22) * * *$ & $0.63(0.23) * *$ \\
\hline Improving & $1.25(0.18) * * *$ & $1.27(0.18) * * *$ & $0.82(0.19) * * *$ & $0.65(0.19) * * *$ \\
\hline High risk & $1.67(0.25) * * *$ & $1.70(0.25) * * *$ & $1.19(0.26) * * *$ & $1.06(0.24) * * *$ \\
\hline Age at Sweep 5 & & $-0.06(0.02) * *$ & $-0.06(0.02) * *$ & $-0.09(0.02) * * *$ \\
\hline \multicolumn{5}{|l|}{ Gender (Ref: } \\
\hline \multicolumn{5}{|l|}{ Male) } \\
\hline Female & & $0.27(0.13) *$ & $0.22(0.12)$ & $0.16(0.12)$ \\
\hline Poverty & & & $1.00(0.19) * * *$ & $0.63(0.19) * * *$ \\
\hline \multicolumn{5}{|l|}{ Ethnicity (Ref: } \\
\hline \multicolumn{5}{|l|}{ White) } \\
\hline Mixed & & & $0.01(0.38)$ & $0.07(0.38)$ \\
\hline Indian & & & $-0.38(0.52)$ & $-0.15(0.53)$ \\
\hline Pakistani and & & & $0.61(0.29) *$ & $0.47(0.31)$ \\
\hline Bangladeshi & & & & \\
\hline Black or Black & & & $0.98(0.36) * *$ & $1.07(0.35) * *$ \\
\hline British & & & & \\
\hline Other (Inc & & & $-0.66(0.60)$ & $-0.56(0.62)$ \\
\hline Chinese) & & & & \\
\hline \multicolumn{5}{|l|}{ Maternal } \\
\hline \multicolumn{5}{|l|}{ Education } \\
\hline Has $1^{\text {st }}$ degree & & & $-1.78(0.19) * * *$ & $-1.48(0.21)$ *** \\
\hline Maternal & & & $0.26(0.22)$ & $0.28(0.21)$ \\
\hline \multicolumn{5}{|l|}{ Depression } \\
\hline Verbal ability & & & & $-0.07(0.01) * * *$ \\
\hline Constant & $33.90(0.08) * * *$ & $41.40(2.33) * * *$ & $41.84(2.28) * * *$ & $49.73(2.21) * * *$ \\
\hline
\end{tabular}

$* \mathrm{p}<0.05 ; * * \mathrm{p}<0.01 ; * * * \mathrm{p}<0.001$

Model 1: Group membership of problem behaviours

Model 2: Model $1+$ Age + Gender

Model 3: Model $2+$ Poverty + Ethnicity + Maternal Education + Maternal Depression

Model 4: Model $3+$ Verbal Ability (Verbal Similarities at age 11) 


\section{Total number of families \\ participating in MCS

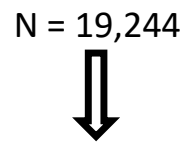

Participating children at MCS2 (age 3), MCS3 (age 5), MCS4 (age 7) and MCS5 (age 11)

$\mathrm{N}=15,808, \mathrm{~N}=15,460, \mathrm{~N}=14,043, \mathrm{~N}=13,469$

Singletons and first-born twins or triplets at MCS2, MCS3, MCS4 and MCS5

$\mathrm{N}=15,591 \mathrm{~N}=15,247 \mathrm{~N}=13,857 \mathrm{~N}=13,287$

Children with at least two ratings on internalising problems $N=14,226$
Children with at least two ratings on conduct problems $\mathrm{N}=14,242$
Children with at least two ratings on hyperactivity/inattention $\mathrm{N}=14,249$

Figure 1 Analytic samples for GBTM 


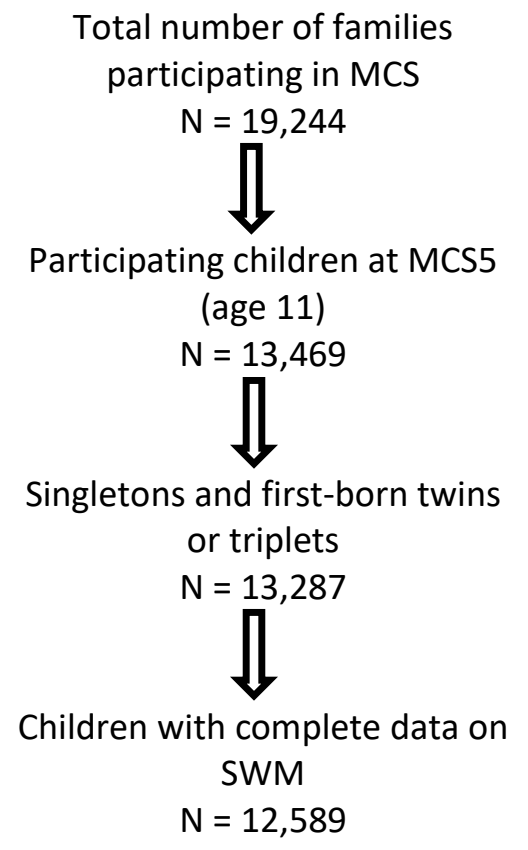

Figure 2 Analytic sample for multiple regression analyses

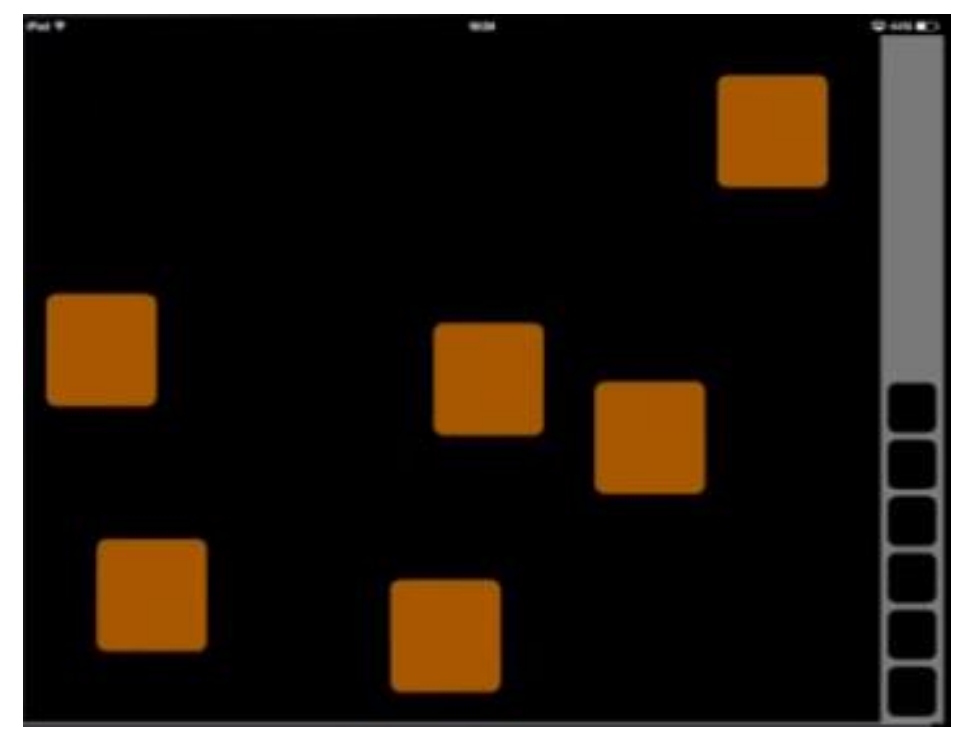

Figure 3 An example of the SWM task on a screen 


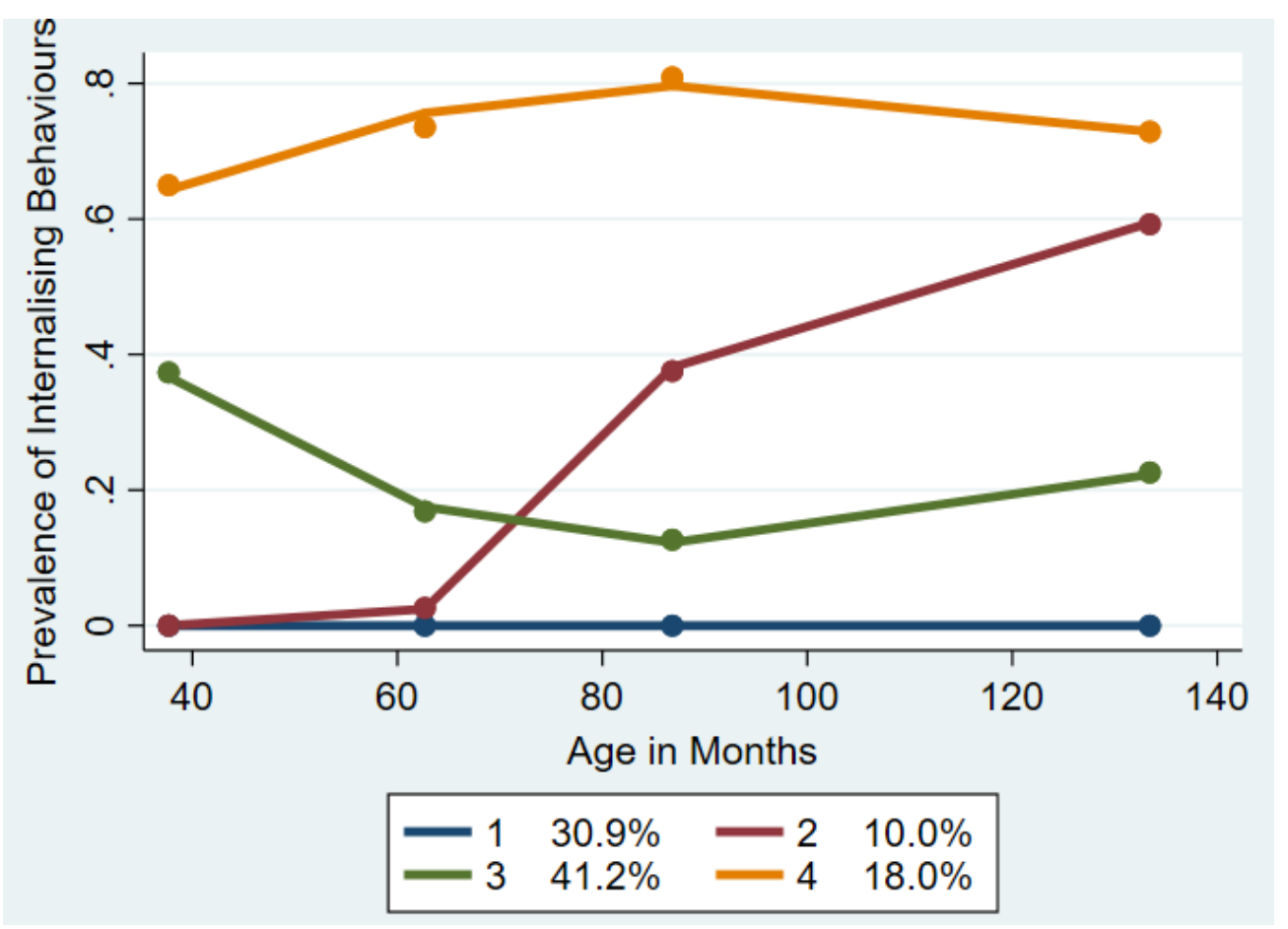

Figure 4 Trajectory groups of internalising problems from ages 3 to 11 years. Shown are estimated trajectories (solid lines), observed group means at each age (dot symbols), and estimated group percentages. 1 - No risk group, 2 - Deteriorating group, 3 - Low risk group, 4 - High risk group.

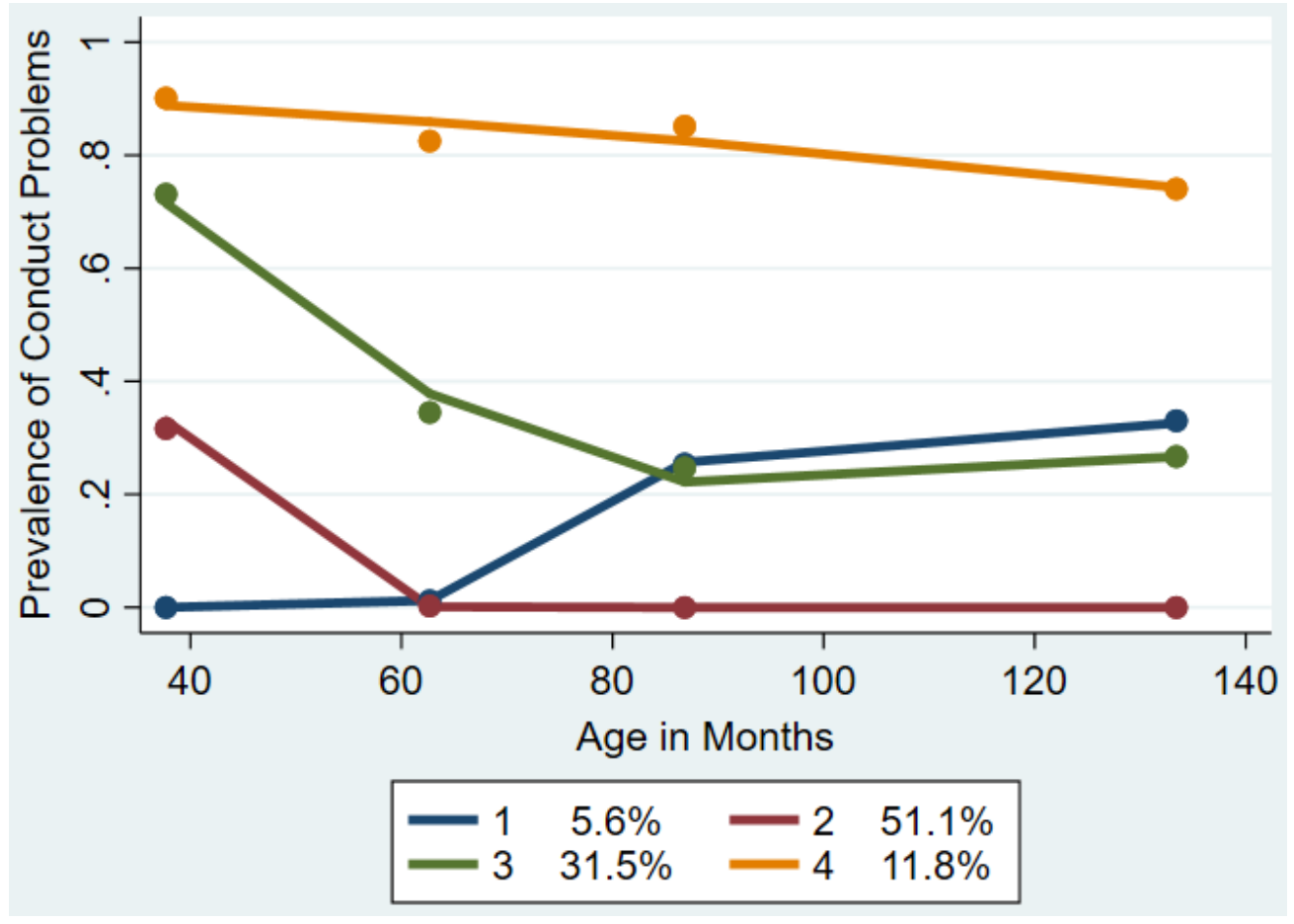

Figure 5 Trajectory groups of conduct problems from ages 3 to 11 years. Shown are estimated trajectories (solid lines), observed group means at each age (dot symbols), and estimated group percentages. 1 Deteriorating group, 2 - Early childhood-limited group, 3 - Improving group, 4 - High risk group. 


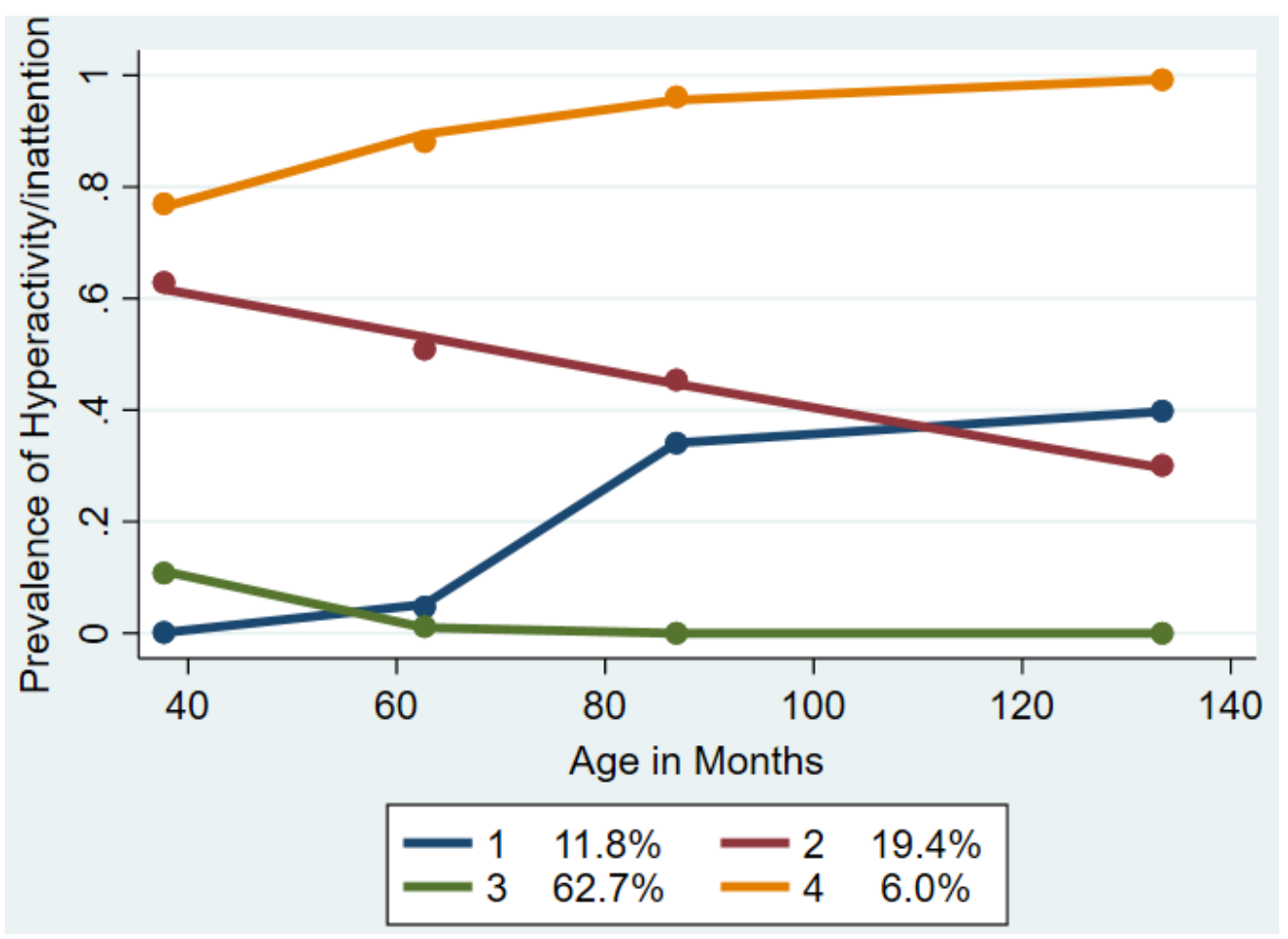

Figure 6 Trajectory groups of hyperactivity/inattention from ages 3 to 11 years. Shown are estimated trajectories (solid lines), observed group means at each age (dot symbols), and estimated group percentages. 1 - Deteriorating group, 2 - Improving group, 3 - Typically developing group, 4 - High risk group. 


\section{Supplementary Material}

Tables S1.1/S1.2/S1.3 present the fit indices of the 2- to 6-group solutions of GBTM applied to examine the developmental trajectories of internalising problems, conduct problems and hyperactivity/inattention from ages 3 to 11 years.

Tables S2.1/S2.2/S2.3 present the fit indices of the 4-group solution of GBTM applied to examine the shapes of the developmental trajectories of internalising problems, conduct problems and hyperactivity/inattention from ages 3 to 11 years. 
Table S1.1 Fit indices of the 2- to 6-group solutions for internalising problems

\begin{tabular}{|c|c|c|c|c|c|c|c|}
\hline $\begin{array}{l}\text { Number } \\
\text { of } \\
\text { Groups }\end{array}$ & $\begin{array}{l}\text { BIC } \\
\left(N^{*}=50778\right)\end{array}$ & $\begin{array}{l}\text { BIC } \\
\left(N^{*}=14226\right)\end{array}$ & AvePP & OCC & $\mathbf{P}$ & $\Pi_{j}$ & $\begin{array}{l}\text { The } \\
\text { Highest } \\
\text { Order } \\
\text { Coefficient } \\
\text { Significant }\end{array}$ \\
\hline \multirow[t]{2}{*}{2} & -26192.62 & -26188.17 & .92 & 4.70 & .73 & .70 & $\mathrm{Y}$ \\
\hline & & & .86 & 15.10 & .27 & .30 & Y \\
\hline \multirow[t]{3}{*}{3} & -26150.84 & -26143.84 & .82 & 5.58 & .33 & .45 & $\mathrm{Y}$ \\
\hline & & & .71 & 3.78 & .53 & .40 & $\mathrm{~N}$ \\
\hline & & & .76 & 18.14 & .14 & .15 & Y \\
\hline \multirow[t]{4}{*}{4} & -26115.09 & -26105.55 & .64 & 3.95 & .48 & .31 & $\mathrm{~N}$ \\
\hline & & & .53 & 11.00 & .06 & .09 & $\mathrm{Y}$ \\
\hline & & & .75 & 4.36 & .30 & .41 & $\mathrm{Y}$ \\
\hline & & & .82 & 19.43 & .17 & .19 & Y \\
\hline \multirow[t]{5}{*}{5} & -26132.82 & --26120.73 & N/A & N/A & N/A & N/A & $\mathrm{N}$ \\
\hline & & & .54 & 15.73 & .03 & .07 & $\mathrm{N}$ \\
\hline & & & .74 & 3.90 & .32 & .42 & $\mathrm{Y}$ \\
\hline & & & .62 & 3.79 & .48 & .30 & $\mathrm{Y}$ \\
\hline & & & .82 & 19.32 & .17 & .19 & $\mathrm{Y}$ \\
\hline \multirow[t]{6}{*}{$6+$} & -26144.71 & -26130.08 & .53 & 12.31 & .06 & .08 & $\mathrm{Y}$ \\
\hline & & & N/A & N/A & N/A & N/A & $\mathrm{Y}$ \\
\hline & & & .70 & 3.98 & .30 & .37 & $\mathrm{Y}$ \\
\hline & & & .67 & 4.03 & .48 & .33 & $\mathrm{Y}$ \\
\hline & & & N/A & N/A & N/A & N/A & $\mathrm{N}$ \\
\hline & & & .80 & 18.69 & .17 & .18 & Y \\
\hline
\end{tabular}

*The smaller $\mathrm{N}$ pertains to the number of individuals in the estimation sample. The larger sample size counts the total number of assessments used in model estimation across persons and time.

+variance matrix is nonsymmetric or highly singular 
Table S1.2 Fit indices of the 2- to 6-group solutions for conduct problems

\begin{tabular}{|c|c|c|c|c|c|c|c|}
\hline $\begin{array}{l}\text { Number } \\
\text { of } \\
\text { Groups }\end{array}$ & $\begin{array}{l}\text { BIC } \\
\left(N^{*}=50918\right)\end{array}$ & $\begin{array}{l}\text { BIC } \\
\left(N^{*}=14242\right)\end{array}$ & AvePP & OCC & $\mathbf{P}$ & $\Pi_{j}$ & $\begin{array}{l}\text { The Highest } \\
\text { Order } \\
\text { Coefficient } \\
\text { Significant }\end{array}$ \\
\hline \multirow[t]{2}{*}{2} & -25715.21 & -25710.75 & .89 & 5.77 & .65 & .59 & $\mathrm{Y}$ \\
\hline & & & .99 & 139.40 & .35 & .41 & Y \\
\hline \multirow[t]{3}{*}{3} & -25570.45 & -25563.45 & .74 & 10.84 & .04 & .21 & $\mathrm{~N}$ \\
\hline & & & .67 & 2.48 & .66 & .45 & $\mathrm{~N}$ \\
\hline & & & .94 & 30.30 & .30 & .34 & Y \\
\hline \multirow[t]{4}{*}{4} & -25480.53 & -25470.97 & .56 & 21.99 & .03 & .06 & Y \\
\hline & & & .78 & 7.26 & .20 & .32 & Y \\
\hline & & & .76 & 3.22 & .65 & .50 & Y \\
\hline & & & .73 & 19.34 & .12 & .12 & $\mathrm{~N}$ \\
\hline \multirow[t]{5}{*}{$5+$} & -25495.15 & -25483.04 & .56 & 22.53 & .03 & .05 & N/A \\
\hline & & & .82 & 9.31 & .40 & .33 & N/A \\
\hline & & & .78 & 7.40 & .20 & .33 & N/A \\
\hline & & & .63 & 8.88 & .24 & .16 & N/A \\
\hline & & & .73 & 18.99 & .12 & .12 & N/A \\
\hline \multirow[t]{6}{*}{$6+$} & -25516.82 & -25502.17 & .82 & 9.31 & .40 & .33 & N/A \\
\hline & & & .56 & 22.50 & .03 & .05 & N/A \\
\hline & & & .63 & 8.88 & .24 & .16 & N/A \\
\hline & & & .78 & 7.40 & .20 & .33 & N/A \\
\hline & & & N/A & N/A & N/A & N/A & N/A \\
\hline & & & .73 & 18.98 & .12 & .12 & N/A \\
\hline
\end{tabular}

*The smaller $\mathrm{N}$ pertains to the number of individuals in the estimation sample. The larger sample size counts the total number of assessments used in model estimation across persons and time.

+ variance matrix is nonsymmetric or highly singular 
Table S1.3 Fit indices of the 2- to 6-group solutions for hyperactivity/inattention

\begin{tabular}{|c|c|c|c|c|c|c|c|}
\hline $\begin{array}{l}\text { Number } \\
\text { of Groups }\end{array}$ & $\begin{array}{l}\text { BIC } \\
\left(N^{*}=50920\right)\end{array}$ & $\begin{array}{l}\text { BIC } \\
\left(N^{*}=14249\right)\end{array}$ & AvePP & OCC & $\mathbf{P}$ & $\Pi_{j}$ & $\begin{array}{l}\text { The Highest } \\
\text { Order } \\
\text { Coefficient } \\
\text { Significant }\end{array}$ \\
\hline \multirow[t]{2}{*}{2} & -21725.90 & -21721.44 & .93 & 7.05 & .69 & .65 & $\mathrm{Y}$ \\
\hline & & & .96 & 50.07 & .31 & .35 & Y \\
\hline \multirow[t]{3}{*}{3} & -21438.03 & -21431.03 & .79 & 22.42 & .08 & .15 & $\mathrm{Y}$ \\
\hline & & & .86 & 3.63 & .73 & .63 & Y \\
\hline & & & .94 & 51.19 & .19 & .22 & $\mathrm{~N}$ \\
\hline \multirow[t]{4}{*}{4} & -21375.33 & -21365.78 & .81 & 4.11 & .61 & .51 & $\mathrm{~N}$ \\
\hline & & & .63 & 17.16 & .08 & .09 & Y \\
\hline & & & .77 & 9.54 & .18 & .26 & Y \\
\hline & & & .84 & 33.55 & .13 & .14 & Y \\
\hline \multirow[t]{5}{*}{$5+$} & -21384.57 & -21372.48 & .89 & 5.36 & .67 & .61 & Y \\
\hline & & & .67 & 104.01 & .02 & .02 & $\mathrm{~N}$ \\
\hline & & & .50 & 21.73 & .01 & .04 & $\mathrm{~N}$ \\
\hline & & & .64 & 6.68 & .19 & .21 & Y \\
\hline & & & .79 & 29.11 & .11 & .12 & Y \\
\hline \multirow[t]{6}{*}{6} & -21389.01 & -21374.36 & .64 & 102.18 & .02 & .02 & $\mathrm{~N}$ \\
\hline & & & .76 & 2.83 & .67 & .52 & Y \\
\hline & & & .59 & 134.24 & .01 & .01 & Y \\
\hline & & & .72 & 9.94 & .10 & .21 & Y \\
\hline & & & .76 & 15.48 & .13 & .17 & $\mathrm{~N}$ \\
\hline & & & .71 & 34.57 & .08 & .07 & Y \\
\hline
\end{tabular}

*The smaller $\mathrm{N}$ pertains to the number of individuals in the estimation sample. The larger sample size counts the total number of assessments used in model estimation across persons and time.

+variance matrix is nonsymmetric or highly singular 
Tables S2.1 Fit indices of the 4-group solution of GBTM applied to examine the shapes of the developmental trajectories of internalising problems

\begin{tabular}{|c|c|c|c|c|c|c|c|}
\hline Model & BIC $\left(N^{*}=50778\right)$ & BIC $\left(N^{*}=14226\right)$ & AvePP & OCC & $\mathbf{P}$ & $\Pi j$ & $\begin{array}{l}\text { The Highest Order } \\
\text { Coefficient Significant }\end{array}$ \\
\hline \multirow[t]{4}{*}{0222} & -26110.35 & -26102.08 & .61 & 3.84 & .47 & .29 & $\mathrm{Y}$ \\
\hline & & & .54 & 10.62 & .06 & .10 & Y \\
\hline & & & .77 & 4.63 & .29 & .42 & Y \\
\hline & & & .83 & 20.11 & .18 & .20 & Y \\
\hline \multirow[t]{4}{*}{2222} & -26115.09 & -26105.55 & .64 & 3.95 & .48 & .31 & $\mathrm{~N}$ \\
\hline & & & .53 & 11.00 & .06 & .09 & Y \\
\hline & & & .75 & 4.36 & .30 & .41 & Y \\
\hline & & & .82 & 19.43 & .17 & .19 & Y \\
\hline \multirow[t]{4}{*}{1222} & -26115.77 & -26106.86 & 61 & 3.84 & .47 & .29 & $\mathrm{~N}$ \\
\hline & & & .54 & 10.62 & .06 & .10 & Y \\
\hline & & & .77 & 4.63 & .29 & .42 & $\mathrm{Y}$ \\
\hline & & & .83 & 20.11 & .18 & .20 & Y \\
\hline 1122 & -26122.11 & -26113.84 & & & & & \\
\hline 2102 & -26122.47 & -26114.84 & & & & & \\
\hline 2012 & -26122.47 & -26114.84 & & & & & \\
\hline 2221 & -26124.33 & -26115.43 & & & & & \\
\hline 2202 & -26124.68 & -26116.41 & & & & & \\
\hline 2122 & -26126.87 & -26117.97 & & & & & \\
\hline 2212 & -26126.87 & -26117.97 & & & & & \\
\hline 2022 & -26127.00 & -26118.73 & & & & & \\
\hline 0212 & -26127.27 & -26119.64 & & & & & \\
\hline $0221+$ & -26127.27 & -26119.64 & & & & & \\
\hline 1221 & -26127.59 & -26119.32 & & & & & \\
\hline 1212 & -26127.59 & -26119.32 & & & & & \\
\hline 1220 & -26128.55 & -26120.91 & & & & & \\
\hline 2111 & -26130.13 & -26122.50 & & & & & \\
\hline 1202 & -26131.87 & -26124.23 & & & & & \\
\hline 2201 & -26133.04 & -26125.41 & & & & & \\
\hline 2021 & -26133.04 & -26125.41 & & & & & \\
\hline 2120 & -26133.48 & -26125.84 & & & & & \\
\hline 2210 & -26133.48 & -26125.84 & & & & & \\
\hline 2220 & -26133.97 & -26125.70 & & & & & \\
\hline 1121 & -26136.58 & -26128.94 & & & & & \\
\hline 1211 & -26136.99 & -26129.36 & & & & & \\
\hline 2211 & -26141.66 & -26133.39 & & & & & \\
\hline 2121 & -26141.86 & -26133.59 & & & & & \\
\hline 0122 & -26142.22 & -26134.58 & & & & & \\
\hline 1112 & -26149.10 & -26141.46 & & & & & \\
\hline 1022 & -26150.07 & -26142.44 & & & & & \\
\hline 1111 & -26159.61 & -26152.61 & & & & & \\
\hline $2112+$ & -26169.29 & -26161.01 & & & & & \\
\hline
\end{tabular}

*The smaller $\mathrm{N}$ pertains to the number of individuals in the estimation sample. The larger sample size counts the total number of assessments used in model estimation across persons and time.

+variance matrix is nonsymmetric or highly singular

In total 32 combination tested including four groups all set as either quadratic or linear (16 combinations e.g., 1221) AND one group set as constant while three other groups are quadratic or linear (16 combinations e.g., 1021) 
Tables S2.2 Fit indices of the 4-group solution of GBTM applied to examine the shapes of the developmental trajectories of conduct problems

\begin{tabular}{|c|c|c|c|c|c|c|c|}
\hline Model & $\begin{array}{l}\text { BIC } \\
(N *=50918)\end{array}$ & $\begin{array}{l}\text { BIC } \\
\left(N^{*}=14242\right)\end{array}$ & AvePP & $\mathrm{OCC}$ & $\mathbf{P}$ & $\Pi j$ & $\begin{array}{l}\text { The } \\
\text { Highest } \\
\text { Order } \\
\text { Coefficient } \\
\text { Significant }\end{array}$ \\
\hline \multirow[t]{4}{*}{2221} & -25475.13 & -25466.21 & .56 & 22.11 & .03 & .05 & $\mathrm{Y}$ \\
\hline & & & .76 & 3.21 & .65 & .50 & $Y$ \\
\hline & & & .78 & 7.39 & .20 & .32 & $\mathrm{Y}$ \\
\hline & & & .73 & 18.47 & .13 & .13 & $Y$ \\
\hline \multirow[t]{4}{*}{$2220+$} & -25477.24 & -25468.96 & .90 & 14.38 & .42 & .39 & $\mathrm{Y}$ \\
\hline & & & .87 & 12.13 & .26 & .35 & Y \\
\hline & & & .71 & 10.94 & .25 & .19 & $\mathrm{~N}$ \\
\hline & & & .72 & 32.29 & .07 & .07 & $\mathrm{Y}$ \\
\hline \multirow[t]{4}{*}{$2212+$} & -25479.89 & -25470.97 & .79 & 7.29 & .25 & .34 & $\mathrm{Y}$ \\
\hline & & & .89 & 12.93 & .42 & .28 & $\mathrm{Y}$ \\
\hline & & & .78 & 29.95 & .08 & .10 & Y \\
\hline & & & .68 & 9.80 & .25 & .18 & $\mathrm{~N}$ \\
\hline \multirow[t]{4}{*}{2222} & -25480.53 & -25470.97 & .56 & 21.99 & .03 & .06 & $\mathrm{Y}$ \\
\hline & & & .78 & 7.26 & .20 & .32 & Y \\
\hline & & & .76 & 3.22 & .65 & .50 & Y \\
\hline & & & .73 & 19.34 & .12 & .12 & $\mathrm{~N}$ \\
\hline \multirow[t]{4}{*}{$1220+$} & -25483.91 & -25476.27 & .91 & 15.37 & .42 & .40 & $\mathrm{Y}$ \\
\hline & & & .73 & 11.38 & .25 & .19 & $\mathrm{~N}$ \\
\hline & & & .87 & 12.49 & .26 & .34 & $\mathrm{Y}$ \\
\hline & & & .68 & 31.14 & .06 & .07 & $\mathrm{Y}$ \\
\hline 1202 & -25487.57 & -25479.92 & & & & & \\
\hline 2120 & -25487.57 & -25479.92 & & & & & \\
\hline 1212 & -25491.43 & -25483.15 & & & & & \\
\hline 2112 & -25491.43 & -25483.15 & & & & & \\
\hline $0221+$ & -25498.12 & -25490.48 & & & & & \\
\hline 0202 & -25498.81 & -25491.80 & & & & & \\
\hline 2020 & -25503.07 & -25496.06 & & & & & \\
\hline 2201 & -25511.26 & -25503.61 & & & & & \\
\hline 0212 & -25516.10 & -25508.46 & & & & & \\
\hline 1022 & -25519.80 & -25512.16 & & & & & \\
\hline 0022 & -25521.62 & -25514.62 & & & & & \\
\hline 2021 & -25523.54 & -25515.89 & & & & & \\
\hline 2122 & -25523.79 & -25514.87 & & & & & \\
\hline $1122+$ & -25523.98 & -25515.70 & & & & & \\
\hline $1221+$ & -25526.82 & -25518.54 & & & & & \\
\hline 1112 & -25528.85 & -25521.20 & & & & & \\
\hline $2202+$ & -25532.69 & -25524.40 & & & & & \\
\hline 2200 & -25558.94 & -25551.93 & & & & & \\
\hline 0220 & -25561.62 & -25554.62 & & & & & \\
\hline 2022 & -25572.08 & -25563.80 & & & & & \\
\hline 0222 & -25572.91 & -25564.63 & & & & & \\
\hline 0122 & -25575.22 & -25567.57 & & & & & \\
\hline 2210 & -25581.31 & -25573.66 & & & & & \\
\hline $1222+$ & -25586.05 & -25577.14 & & & & & \\
\hline 2102 & -25603.05 & -25595.41 & & & & & \\
\hline 2012 & -25658.54 & -25650.90 & & & & & \\
\hline 1121 & -25697.13 & -25689.49 & & & & & \\
\hline $1111+$ & -25704.18 & -25697.17 & & & & & \\
\hline 2121 & -25706.99 & -25698.70 & & & & & \\
\hline $1211+$ & -25709.60 & -25701.95 & & & & & \\
\hline $2111+$ & -25709.60 & -25701.95 & & & & & \\
\hline 2002 & -25794.68 & -25787.67 & & & & & \\
\hline $2211+$ & -25869.78 & -25861.50 & & & & & \\
\hline
\end{tabular}


*The smaller $\mathrm{N}$ pertains to the number of individuals in the estimation sample. The larger sample size counts the total number of assessments used in model estimation across persons and time.

+variance matrix is nonsymmetric or highly singular

In total 38 combinations tested including four groups all set as either quadratic or linear (16 combinations

e.g., 1221) AND one or two groups set as constant while other groups are quadratic or linear (22

combinations e.g., 1021; 2021) 
Tables 2.3 Fit indices of the 4-group solution of GBTM applied to examine the shapes of the developmental trajectories of hyperactivity/inattention

\begin{tabular}{|c|c|c|c|c|c|c|c|}
\hline Model & $\begin{array}{l}\text { BIC } \\
\left(N^{*}=50920\right)\end{array}$ & $\begin{array}{l}\text { BIC } \\
\left(N^{*}=14249\right)\end{array}$ & AvePP & OCC & $\mathbf{P}$ & $\Pi j$ & $\begin{array}{l}\text { The Highest } \\
\text { Order } \\
\text { Coefficient } \\
\text { Significant }\end{array}$ \\
\hline \multirow[t]{4}{*}{1222} & -21369.67 & -21360.75 & .83 & 4.15 & .63 & .54 & $\mathrm{Y}$ \\
\hline & & & .56 & 26.48 & .05 & .05 & Y \\
\hline & & & .84 & 14.30 & .18 & .27 & Y \\
\hline & & & .84 & 30.64 & .14 & .14 & Y \\
\hline \multirow[t]{4}{*}{2122} & -21369.67 & -21360.75 & .56 & 26.48 & .05 & .05 & Y \\
\hline & & & .83 & 4.15 & .63 & .54 & Y \\
\hline & & & .84 & 14.30 & .18 & .27 & Y \\
\hline & & & .84 & 30.64 & .14 & .14 & Y \\
\hline \multirow[t]{4}{*}{2121} & -21374.52 & -21366.24 & .71 & 18.75 & .08 & .12 & Y \\
\hline & & & .80 & 15.94 & .15 & .20 & Y \\
\hline & & & .86 & 3.88 & .70 & .61 & Y \\
\hline & & & .72 & 37.14 & .07 & .06 & Y \\
\hline \multirow[t]{4}{*}{2222} & -21375.33 & -21365.78 & .81 & 4.11 & .61 & .51 & $\mathrm{~N}$ \\
\hline & & & .63 & 17.16 & .08 & .09 & Y \\
\hline & & & .77 & 9.54 & .18 & .26 & Y \\
\hline & & & .84 & 33.55 & .13 & .14 & $\mathrm{Y}$ \\
\hline \multirow[t]{4}{*}{2221} & -21378.72 & -21369.81 & .73 & 19.39 & .08 & .12 & $\mathrm{Y}$ \\
\hline & & & .86 & 3.83 & .70 & .61 & Y \\
\hline & & & .80 & 15.84 & .15 & .20 & $\mathrm{~N}$ \\
\hline & & & .72 & 37.31 & .07 & .06 & Y \\
\hline 2220 & -21387.07 & -21378.79 & & & & & \\
\hline 2021 & -21391.97 & -21384.33 & & & & & \\
\hline 2020 & -21394.06 & -21387.05 & & & & & \\
\hline 0212 & -21403.41 & -21395.77 & & & & & \\
\hline $2012+$ & -21418.57 & -21410.93 & & & & & \\
\hline 2022 & -21419.22 & -21410.94 & & & & & \\
\hline 0222 & -21421.91 & -21413.63 & & & & & \\
\hline 2102 & -21423.25 & -21415.61 & & & & & \\
\hline 1202 & -21423.25 & -21415.61 & & & & & \\
\hline 1122 & -21423.99 & -21415.71 & & & & & \\
\hline 1112 & -21424.18 & -21416.54 & & & & & \\
\hline 2002 & -21426.30 & -21419.30 & & & & & \\
\hline 0022 & -21426.31 & -21419.30 & & & & & \\
\hline 1121 & -21428.86 & -21421.22 & & & & & \\
\hline $2112+$ & -21429.60 & -21421.32 & & & & & \\
\hline 1212 & -21429.61 & -21421.33 & & & & & \\
\hline 2200 & -21432.00 & -21424.99 & & & & & \\
\hline $2212+$ & -21435.00 & -21426.08 & & & & & \\
\hline 2202 & -21437.14 & -21428.86 & & & & & \\
\hline 2120 & -21437.26 & -21429.62 & & & & & \\
\hline 1111 & -21439.17 & -21432.17 & & & & & \\
\hline $1211+$ & -21444.59 & -21436.95 & & & & & \\
\hline $2111+$ & -21444.59 & -21436.95 & & & & & \\
\hline $1221+$ & -21447.98 & -21439.70 & & & & & \\
\hline $1220+$ & -21450.71 & -21443.07 & & & & & \\
\hline $0220+$ & -21451.46 & -21444.45 & & & & & \\
\hline 0202 & -21452.15 & -21445.15 & & & & & \\
\hline $0221+$ & -21453.51 & -21445.86 & & & & & \\
\hline $0122+$ & -21457.15 & -21449.51 & & & & & \\
\hline 1022 & -21457.36 & -21449.72 & & & & & \\
\hline $2210+$ & -21629.48 & -21621.84 & & & & & \\
\hline $2211+$ & -21632.78 & -21624.50 & & & & & \\
\hline $2201+$ & -21749.89 & -21742.25 & & & & & \\
\hline
\end{tabular}

*The smaller N pertains to the number of individuals in the estimation sample. The larger sample size counts the total number of assessments used in model estimation across persons and time.

+variance matrix is nonsymmetric or highly singular

In total 38 combination tested including four groups all set as either quadratic or linear (16 combinations e.g., 1221) AND one or two groups set as constant while other groups are quadratic or linear (22 combinations e.g., 1021; 2021) 